\title{
Einleitung: \\ Widerspruchsgeist eines Beamtendichters
}

In seinem Monumentalwerk Der Mann ohne Eigenschaften erinnert sich Robert Musil (1880-1942) so ironisch wie anerkennend an den europaweiten Ausbruch der Moderne. Die kreativen Impulse und Widersprüchlichkeiten der Jahrhundertwende erfuhren durch das „magische Datum“ einen besonderen Ausdruck:

\begin{abstract}
Aus dem ölglatten Geist der zwei letzten Jahrzehnte des neunzehnten Jahrhunderts hatte sich plötzlich in ganz Europa ein beflügelndes Fieber erhoben. Niemand wußte genau, was im Werden war; niemand vermochte zu sagen, ob es eine neue Kunst, ein neuer Mensch, eine neue Moral oder vielleicht eine Umschichtung der Gesellschaft sein solle. Darum sagte jeder davon, was ihm paßte. [...] Es entwickelten sich Begabungen, die früher erstickt worden waren oder am öffentlichen Leben gar nicht teilgenommen hatten. Sie waren so verschieden wie nur möglich, und die Gegensätze ihrer Ziele waren unübertrefflich. [...] Man begeisterte sich für das Heldenglaubensbekenntnis und für das soziale Allemannsglaubensbekenntnis; man war gläubig und skeptisch, naturalistisch und preziös, robust und morbid; man träumte von alten Schloßalleen, herbstlichen Gärten [...], von Schmiede- und Walzwerken, nackten Kämpfern, Aufständen der Arbeitssklaven, menschlichen Urpaaren und Zertrümmerung der Gesellschaft. Das waren freilich widersprüchliche und höchst verschiedene Schlachtrufe, aber sie hatten einen gemeinsamen Atem; würde man jene Zeit zerlegt haben, so würde ein Unsinn herausgekommen sein wie ein eckiger Kreis, der aus hölzernem Eisen bestehen will, aber in Wirklichkeit war alles in einem schimmernden Sinn verschmolzen. ${ }^{1}$
\end{abstract}

Viele der im Zitat genannten Merkmale der Moderne, die Gleichzeitigkeit von Tradition und Progression in den Künsten, technologische Errungenschaften, Urbanisierung, das Aufeinandertreffen neuer und alter Moralvorstellungen sowie der sich vollziehende Strukturwandel finden sich so oder ähnlich in den ideologischen und poetologischen Stellungnahmen, Distanzierungen und Selbstverortungen Richard Schaukals.

Der 1874 in Brünn (Brno) geborene Dichter, Kritiker, Übersetzer und Ministerialbeamte gehörte zu den streitbaren literarischen Akteuren der ,kritischen Moderne ${ }^{2}{ }^{2}$ Dass Schaukal biographisch wie werkästhetisch nicht leicht einordbar ist, mag unter anderem an der mit seinem Tod im Jahre 1942 hinterlassenen

\footnotetext{
1 Robert Musil: Gesamtausgabe. Bd. 1. Erstes Buch: Der Mann ohne Eigenschaften. Hg. von Walter Fanta. Salzburg/Wien 2016, S. 84-85.

2 Vgl. Allan Janik: Vienna 1900 Revisited. Paradigms and Problems. In: Rethinking Vienna 1900. Hg. von Steven Beller. New York/Oxford 2001, S. 27-56; vgl. auch Michael Burri: Theodor Herzl and Richard Schaukal. Self-Styled Nobility and the Sources of Bourgeois Belligerence in Prewar Vienna. In: Rethinking Vienna 1900, S. 105-131.
} 
Fülle schriftlicher Äußerungen liegen sowie an der Komplexität seiner teils widersprüchlichen Texte. Ein zentrales Lebensthema blieb aber die Retrophilie. Schaukals ästhetizistische Vergangenheitssehnsucht der frühen Jahre mündete nach dem Ende der Donaumonarchie in politisch aufgeladene, nicht minder rückwärtsgewandte Zeit- und Gesellschaftskritiken. 1925 kam es etwa im Zuge des tödlichen Attentats auf Hugo Bettauer (1872-1925) zu einer kurzen Korrespondenz mit Robert Musil, seinerzeit stellvertretender Vorsitzender des Schutzverbandes Deutscher Schriftsteller in Österreich. Schaukal drohte mit seinem Austritt aus dem SDSOe, da der Verband nach dem Anschlag auf Bettauer gegen die Hetze in der rechtskonservativen Presse Stellung bezogen hatte. Die Beschwerdebriefe und eine nicht veröffentlichte Polemik zum ,Fall Bettauer zeugen von Schaukals tiefwurzelndem Konservatismus. ${ }^{3}$ „Jedes der rund achtzig Werke Schaukals ist in der Grundtendenz konservativ. Der Dichter ist weder thematisch, noch sprachlich, weder formal, noch stilistisch ein Neuerer oder Experimentierer, bestenfalls ein genialer ,Anverwandler` und ,Adapteur““, so Claudia Girardi. ${ }^{4}$ Dabei habe er sich „der Einordnung in starre Kategorien Zeit seines Lebens entzogen“, wollte keinen literarischen Regeln, Schulen oder Gruppen zugehören und aus sich heraus dichterisch produktiv sein, wie Andreas Wicke mit Blick auf Schaukals Lyriktheorie festhält. ${ }^{5} \mathrm{Zu}$ diesem Zweck griff der Dichter auf einen klassischen Geniebegriff zurück, an dem er auch in seinen biographischen und literaturkritischen Arbeiten festhielt. ${ }^{6}$

Schaukals restaurative Werke und kulturkritische Essays verdichteten sich gemeinsam mit seinem aristokratischen Habitus zu einer nostalgischen Lebensweise, ohne dabei die Entwicklungen der Gegenwart oder ihre technischen Mittel für eine öffentlichkeitswirksame Selbstdarstellung - etwa in Form von inszenierten Fotografien und Radiovorlesungen - außer Acht zu lassen. Dass

3 Schaukal sah von der Veröffentlichung ab und trat aus dem Verband nicht aus, da Bettauer seinen Verletzungen erlag. Siehe die Briefe an Musil im Schaukal-Nachlass der Wienbibliothek (im Folgenden zit. als S-NL, WB). Dominik Pietzcker widmet dem Fall Bettauer einen Exkurs; vgl. Pietzcker: Richard von Schaukal. Ein österreichischer Dichter der Jahrhundertwende. Würzburg 1997, S. 240-242. Vgl. dazu auch Murray G. Hall: Der Fall Bettauer. Wien 1978, S. 70-76.

4 Claudia Girardi: Der Dichter Richard von Schaukal als „Konservator“ der guten alten Zeit. In: Konservative Profile. Ideen \& Praxis in der Politik zwischen FM Radetzky, Karl Kraus und Alois Mock. Hg. von Ulrich E. Zellenberg. Graz/Stuttgart 2003, S. 285-302, hier S. 292.

5 Andreas Wicke: Richard Schaukal und die Lyriktheorie der Jahrhundertwende. In: Modern Austrian Literature, Bd. 34, Nr. 3-4 (2001), S. 79-93, hier S. 82.

6 Vgl. Wicke: Richard Schaukal und die Lyriktheorie der Jahrhundertwende, S. 86-87. 
Schaukal die Architektur von Adolf Loos (1870-1933) früh würdigte und im gleichen Maße zu schätzen wusste wie Renaissance- und Barockmalerei, fügt sich in das widerspruchsbeladene Bild des kaisertreuen Beamtendichters, der Antisemit war und den Anschluss Österreichs an Hitler-Deutschland ablehnte.

Seine Rolle als Verfechter reaktionärer Positionen und die Verbindung von politischem und kritischem Wirken sind kaum zu überschätzen. Vor allem Schaukals Essays erreichten nicht nur in Wien eine große Leserschaft, sondern im gesamten deutschen Sprachraum. Er publizierte in Zeitungen und Zeitschriften mit Redaktionssitz in Brünn, Leipzig, München, Wien, Berlin, Essen, Nürnberg, Darmstadt, Stuttgart und Chemnitz, um nur einige zu nennen. Die 1929 gegründete ,SchaukalGesellschaft‘ zählte zeitweise über 300 Mitglieder und avancierte in der Zwischenkriegszeit zu einem Zentrum konservativer Ideologie. Doch im Laufe der 1930er Jahre sank die Mitgliederzahl rapide; manche Austritte wurden mit Schaukals ambivalenter Haltung zum Nationalsozialismus begründet, von dem er sich nach anfänglichen Sympathiebekundungen öffentlich distanzierte. ${ }^{7}$

Die letzten Lebensjahre des pensionierten Sektionschefs waren von materieller Not und Verbitterung über fehlende Anerkennung geprägt. In den späten Briefen bittet Schaukal seine Kontakte nicht mehr nur um literarische Vermittlung, sondern auch um Brennholz, Kohle, Nahrungsmittel.

In Richard Schaukals Biographie lassen sich zwei wiederkehrende Momente ausmachen, die für seine Position im literarischen Feld und in den Netzwerken der Moderne ganz entscheidend waren. Zum einen setzte er sich kontinuierlich - und nicht nur als Vertreter der Dekadenzdichtung - mit bürgerlichen und antibürgerlichen Verhaltensmustern auseinander. Diese Auseinandersetzung erfolgte in Form von regelmäßigen Äußerungen über die Buch-, Schreib- und Lesekultur. Die Mediatisierung und Verbreitung der Lesekompetenz empfand Schaukal ebenso wie die fortschreitende Ökonomisierung von Presse und Literatur als konkrete Statusbedrohung. Auch deshalb stellte er sich (öffentlich) die Frage, ob er am kulturkritischen Diskurs und politischen Betrieb partizipieren oder ob er dieses Engagement verweigern sollte. Schaukal wählte zur Verbreitung seiner Kulturkritik einen Zwischenweg, der seiner inszenierten Weltabgewandtheit und einem im Grunde doch auch ideologischen Wirken gleichermaßen Rechnung tragen sollte. Dies mündete in kontradiktorische Selbstreflexionen und vielfach wiederholte Individualitätsbekenntnisse:

7 Vgl. Richard Schaukal: Nationalismus. In: Der Christliche Ständestaat, 1. Jg., Nr. 23 (1934), S. 3-4; Schaukal: Was wird aus Deutschland? In: Der Christliche Ständestaat, 1. Jg., Nr. 32 (1934), S. 9-10. 
[I]ch bin der „zurückhaltendste Mensch von der Welt“ und dennoch, wenn ich spreche, wenn ich schreibe, bekenntnisfroh wie wenige. Und während ich die einzelnen Menschen fast scheu vermeide, gebe ich mich in meinen Büchern schrankenlos mit meinem Heimlichsten hin. Ich fliehe die Öffentlichkeit und stürze mich doch als Schriftsteller in sie, wo sie am breitesten ist. ${ }^{8}$

Zum Teil speiste sich diese Widersprüchlichkeit aus dem fast schon stereotypen Topos des österreichischen Beamtendichters, der zwischen staatlicher Pflichterfüllung und künstlerischer Neigung aufgerieben wird.

Richard Schaukals Beamtenlaufbahn begann nach einem vierjährigen Studium der Rechtswissenschaften an der Universität Wien im Jahr 1897 und endete mit seinem freiwilligen Austritt aus dem Staatsdienst 1919. Von sehr viel längerer Dauer war hingegen sein Wirken als Schriftsteller. Schaukal veröffentlichte bereits als 16-jähriger Gymnasiast in seiner Heimatstadt Brünn erste Gedichte im Mährisch-Schlesischen Correpondenten. Auch wenn der Dichter in den Beiträgen einer Selbstdarstellung (1934) eine tendenziell positive Grundhaltung zur gutbürgerlichen Herkunft an den Tag legt, war sein Verhältnis zum Bürgertum aufgrund soziokultureller wie historischer Brüche belastet.

Die idealtypische Auffassung vom Erfolgsmodell Bürgertum hatte sich spätestens zu Beginn des 20. Jahrhunderts verflüchtigt. Über Besitz und Bildung, Eigeninteresse und Gemeinwohlorientierung sowie über zweckfreie Kreativität und zweckgebundene Rationalität relativ autonom zu verfügen, waren die ursprünglichen Merkmale eines bürgerlichen Selbstverständnisses. ${ }^{9}$ Pierre Bourdieus Definition des Bürgerlichen trifft überwiegend auch auf Schaukal zu. Allerdings war das Bürgertum spätestens nach dem Ersten Weltkrieg keine homogene soziale Klasse mehr. ${ }^{10}$ Seine Vertreter entstammten zunehmend Gesellschaftsschichten, die sich nicht mehr eindeutig von anderen Milieus abgrenzen ließen, sei es vom Adel oder von dem der Arbeiter und Angestellten. Die Kategorie des Bürgerlichen fächerte sich weiter auf, umfasste Ladenbetreiber ebenso wie mittelständische Unternehmer, Ärzte, Juristen oder das Industriebürgertum.

Ein Resultat der zunehmenden Komplexität und Heterogenität der sozialen Verhältnisse war - so auch bei Schaukal - die Hinwendung zum Erbadel bei

8 Schaukal: Beiträge zu einer Selbstdarstellung. Wien 1934, S. 1.

9 Vgl. Manfred Hettling: Bürgerliche Kultur - Bürgerlichkeit als kulturelles System. In: Sozialund Kulturgeschichte des Bürgertums. Eine Bilanz des Bielefelder Sonderforschungsbereichs (1986-1997). Hg. von Peter Lundgreen. Göttingen 2000, S. 319-339, hier S. 324-325.

10 Vgl. Pierre Bourdieu: Die feinen Unterschiede. Kritik der gesellschaftlichen Urteilskraft. Aus dem Franz. von Bernd Schwibs und Achim Russer. Frankfurt am Main 1994, S. 176-187, vor allem S. 176-177 und S. 182. Weitere Merkmale sind laut Bourdieu Geschlecht, Alter, Beruf, Wohnort sowie die soziale Herkunft. 
gleichzeitiger Distanzierung vom sogenannten niederen Stand, die sich zur antidemokratischen Tendenz auswuchs. Man könne die Gesellschaft, so Schaukal in einem Essay über Frank Wedekind (1864-1918), „nicht anders als durch die puerile Gewalttätigkeit der Französischen Revolution bekämpfen. Die rationalistischen Aufklärer entfesselten den Mob gegen die sieche Macht [. . .]. Der Mob bemächtigt sich der Macht und mißbraucht sie so lange, bis er sich das Legitimitätsprinzip wieder über den Nacken werfen läßt.“11

Aus dem blutig niedergeschlagenen Coup d’État vom 2. Dezember 1851 zog Gustave Flaubert (1821-1880) eine ähnliche Erkenntnis, die auch Schaukal, Übersetzer und Kenner seiner Werke, befürwortet haben dürfte: „Nämlich, daß man das Gewöhnliche überhaupt nicht braucht, das Element der Menge, Majoritäten, öffentliche Anerkennung, Bestätigung. 89 hat das Königtum und den Adel zu Fall gebracht, 48 die Bourgeoisie und 51 das Volk [...]. Die soziale Gleichheit ist in geistige übergegangen."12 Wenige Monate zuvor hatte Flaubert die Adressatin seiner Briefe gefragt: „Schert sich die Masse nicht einen Dreck um Kunst, Dichtung, Stil? Sie braucht das alles gar nicht. Schafft ihr seichte Komödien, Abhandlungen über Gefängnisarbeit, über Arbeitersiedlungen und die augenblicklichen materiellen Interessen, meinetwegen. “13

Mit Blick auf Schaukal und Österreich könnte Flauberts historischer Abriss durch das Jahr 1873 ergänzt werden, als ein Großteil des liberalen Bürgertums zumindest ins Straucheln geraten war. Der Liberalismus hatte die Wirtschaft beflügelt und die davon profitierenden Unternehmer ließen sich entlang der neu geschaffenen Wiener Ringstraße ihre Palais errichten. Doch der Börsenkrach von 1873 stellte ein prägendes Ereignis dar, seine Auswirkungen bekam auch die nachfolgende Generation noch zu spüren. Die den bürgerlichen Sprossen zuvor in die Wiege gelegten beruflichen Perspektiven und sozialen Privilegien waren gegen Ende des Jahrhunderts nicht mehr gesichert. Zum anderen strebten die Töchter und Söhne der liberalen Ära auch von sich aus andere Lebensmodelle an. Das „goldene Zeitalter der Sicherheit“ (Stefan Zweig, 1881-1942) hatte erst zu kultureller Hochkonjunktur geführt, mündete dann aber zunehmend in urbane Betriebsamkeit, in der auch politische Themen behandelt und soziale Fragen gestellt werden mussten.

11 Schaukal: Frank Wedekind. Skizze zu einem Porträt. In: WE. Bd. 5: Über Dichter. München/ Wien 1966, S. 62-72, hier S. 69.

12 Brief Gustave Flauberts an Louise Colet vom 22. September 1853, in: Flaubert: Die Briefe an Louise Colet. Mit allen erhaltenen Briefen und Tagebuchnotizen von Louise Colet an Gustave Flaubert und einem Vorwort von Julian Barnes. Aus dem Franz. und mit Anm. von Cornelia Hasting. Zürich 1995, S. 815-816.

13 Brief Flauberts an Colet vom 20. Juni 1853, in: Flaubert: Die Briefe an Louise Colet, S. 715. 
Edward Timms beschreibt mit Blick auf Karl Kraus (1874-1936), dass die moralische Haltung der aus privilegierten Verhältnissen stammenden Schriftsteller in Wien auch deshalb zu produktivem Zorn geführt habe, weil die Position in der und zur Gesellschaft zunehmend infrage gestellt wurde. Daraus resultierten multiple Identitätskonstruktionen und biographische Kategorisierungsversuche, die Timms in Bezug auf Kraus darlegt:

Qua Geburt war er Jude, qua Nationalität Österreicher, qua Wohnort Wiener, qua Sprache Deutscher, qua Beruf Journalist, qua gesellschaftlichem Status Bürger und qua wirtschaftlicher Stellung Privatier. Inmitten der ideologischen Turbulenzen Österreich-Ungarns erschienen alle diese ihm zugeschriebenen Identitäten wie Verzerrungen. ${ }^{14}$

Die Aufhebung gesellschaftlicher Strukturen und Orientierungspunkte erklärt vielleicht den wütenden Eifer, mit dem Akteure des öffentlichen Lebens ihre Kulturund Zivilisationskritik äußerten. Schaukals befremdliches Divergieren zwischen teils heftigen öffentlichen Invektiven und seinem gesetzten aristokratischen Habitus, sein Auftreten als Antiintellektueller, hetzender Antisemit, Mann von Welt, würdevoller Ministerialbeamter, Wohltäter, keineswegs erfolgloser Dichter und gesuchter Kritiker sind insgesamt Ausdruck einer Selbstverortung, die vor dem Hintergrund historischer Brüche umso deutlicher wird; die Verfügbarkeit und der Einsatz der in jedem Feld seines Agierens spezifischen Kapitalsorten (nach Bourdieu) zeichnet ein aufschlussreiches Bild der gesellschaftlichen Diversifizierung und des Positionenwechsels in den Sphären der sozialen Welt, die mit Anbruch der Moderne auch zunehmend komplexere sozioökonomische Spielregeln hervorbrachte. Eine wesentliche Rolle spielte für Schaukals Selbstwahrnehmung die Verbindung von ,inkorporierten“ Merkmalen (Aristokratismus) und ,objektivierten“ Merkmalen (ökonomische und kulturelle Güter, beispielsweise Bücher in großer Zahl). ${ }^{15}$ Beide erfuhren zu Schaukals Lebzeiten in ihrer symbolischen, politischen und gesellschaftlichen Wertigkeit Veränderungen, die mit einer zunehmenden Literarisierung einhergingen.

Lesekultur und Publikationslandschaft veränderten sich vor allem um die Jahrhundertwende infolge industrieller Entwicklungen rasant und beschleunigten auch die Distribution von Wissen und Information in nie dagewesenem Ausmaß. ${ }^{16}$ Wie sehr Schaukal mit der Ökonomisierung des Lesens haderte, wird aus seinen

14 Edward Timms: Karl Kraus. Satiriker der Apokalypse. Aus dem Engl. von Max Looser und Michael Strand. Wien 1995, zit. nach Das Kraus-Projekt. Aufsätze von Karl Kraus mit Anmerkungen von Jonathan Franzen. Unter Mitarbeit von Paul Reitter und Daniel Kehlmann. Aus dem Engl. von Bettina Abarbanell. Reinbek bei Hamburg 2014, S. 103.

15 Die Termini gehen auf Pierre Bourdieu zurück und werden noch näher erläutert.

16 Vgl. Wolfgang Kaschuba: Die Überwindung der Distanz. Zeit und Raum in der europäischen Moderne. Frankfurt am Main 2004, S. 16. 
emotionsgeladenen Essays zu den Themen Buch, Lesen und Kindheitslektüre ersichtlich, die sich mit der Rückwärtsgewandtheit zum kulturkritischen Zentraltopos verbinden. ${ }^{17}$ Die im 19. Jahrhundert sich unregelmäßig verbreitende und in diffusen Schüben wachsende Literarisierung gelangte zu Beginn des 20. Jahrhunderts in Österreich-Ungarn vorläufig zum Abschluss. ${ }^{18}$ Der nicht adäquat zu übersetzende Begriff ,literacy‘, den Jürgen Osterhammel in seiner Studie verwendet, bezieht sich auf ein breites, über die bloße Alphabetisierung hinausreichendes Bedeutungsspektrum,

das von der Fähigkeit, eine Unterschrift unter eine Heiratsurkunde zu setzen, über die Gewohnheit regelmäßiger Lektüre sakraler Texte und die Praxis privaten Briefeschreibens bis zur aktiven Teilnahme am öffentlichen literarischen Leben reicht. [.. . ] Ein Umgang mit der Kulturtechnik des Lesens (und sekundär auch des Schreibens), der die Teilnahme an weiteren Kommunikationskreisen als der Sprech- und Hörgemeinschaft unter Anwesenden ermöglicht. Wer lesen kann, wird zum Mitglied einer überlokalen Öffentlichkeit. Zugleich setzt er sich auch neuen Möglichkeiten der Manipulation und Fremdsteuerung aus. ${ }^{19}$

Schaukal reagierte ambivalent auf den Wandel von der funktionalen Lese- und Schreibfähigkeit hin zu einer neuen symbolischen und sozialen Bedeutung. Einerseits machte er sich die medialen und technischen Neuerungen für die kulturelle, politische oder literarische Vermittlung seines Schaffens und zur Selbstpositionierung innerhalb einer „imaginierten Gemeinschaft“ $\mathrm{zu}$ eigen. ${ }^{20}$ Andererseits wetterte er in kulturkritischen Essays gegen den Feuilletonismus, da dieser Literatur und Pressemeldung vermischen und das Bewusstsein für literarische Kunst schwächen würde. Mitverantwortlich für eine negative soziokulturelle Entwicklung sei vordergründig ein bereits etabliertes Medium, das aber mit dem industriellen Fortschritt sowie infolge zunehmender Literarisierung und Urbanisierung um 1900 an Attraktivität für eine breitere Masse gewann: die Zeitung.

17 Eine Übersicht über Schaukals Lesegewohnheiten und -stoffe gibt Claudia Warum: Richard von Schaukal als Kritiker und Übersetzer aus dem Französischen. Diss. Universität Wien, 1993, Bd. 1, S. 5-9.

18 Vgl. Jürgen Osterhammel: Die Verwandlung der Welt. Eine Geschichte des 19. Jahrhunderts. München 2009, S. 1118. Weite Teile der Bevölkerung waren zu diesem Zeitpunkt des Lesens und Schreibens mächtig, auch wenn anzumerken bleibt, dass bis zum Ende der Vielvölkermonarchie der Literarisierungsgrad zwischen Peripherie und Zentrum sowie zwischen den einzelnen in den Kronländern lebenden Ethnien weiter differierte; vgl. Martin Mutschlechner: Die Gleichzeitigkeit des Ungleichzeitigen: Alphabetisierung als Gradmesser der Entwicklung. http://ww1.habsburger. net/de/kapitel/die-gleichzeitigkeit-des-ungleichzeitigen-alphabetisierung-als-gradmesser-derentwicklung (zuletzt aufgerufen am 31. Juli 2019).

19 Osterhammel: Die Verwandlung der Welt, S. 1117-1118.

20 Osterhammel: Die Verwandlung der Welt, S. 1118. 
Als Dichter und Kritiker hätte Schaukal die zunehmende Lesefähigkeit als Vergrößerung des literarischen Marktes gutheißen können. Doch erstens steigerte sie die Nachfrage nach populären und feuilletonistischen Lesestoffen, Genres, die er nicht bedienen mochte, und zweitens ermöglichte sie bildungsfernen Schichten kulturelle Teilhabe und politischen Austausch. ${ }^{21}$ Als Verfechter des Ständestaates befürwortete Schaukal keineswegs die Demokratisierung des Lesens oder Aktivitäten des ,dritten Standes‘ in den Feldern Bildung und Kultur. Laut Bourdieu sind Künstler und Intellektuelle

hin- und hergerissen zwischen ihrem Interesse [. . . ] an der Eroberung des Marktes durch die entsprechenden Unternehmungen, sich ein breites Publikum zu erschließen, und andererseits der ängstlichen Sorge um die Exklusivität ihrer Stellung im Kulturleben, die einzige objektive Grundlage ihrer Außergewöhnlichkeit; sie unterhalten daher zu allem, was mit „Demokratisierung der Kultur“ zu tun hat, eine äußerst ambivalente Beziehung [...]. ${ }^{22}$

„Kein Blatt ist je stärker gelesen als dieses. Ganz Wien wird nolens volens Genosse“, schreibt Anton Kuh (1890-1941) 1918 in einem Essay über die Bedeutung der Arbeiter-Zeitung, ${ }^{23}$ die Schaukal ebenso abonniert hatte wie Die Fackel. Ähnlich Karl Kraus, der das Zeitungswesen in Anspielung auf seine irrationale Bannkraft und Druckerfarbe als ,schwarze Magie‘ bezeichnete, lehnte Schaukal die Vermischung von Literatur und Berichterstattung strikt ab. Schuld am „geistigen Ruin der Wiener Gesellschaft“ trügen die auf die Form bedachten Zeitungen und das Kaffeehaus; die ausgedehnten, mit dem Zeitunglesen verbundenen Kaffeehausbesuche verkämen zum ästhetischen Selbstzweck und verringerten die Zeit, welche der kulturellen Bildung und moralischen Erziehung dienen sollte, so 1891 der sozialliberale Kulturpublizist und zeitweilige Redakteur der Arbeiter-Zeitung Edmund Wengraf (1860-1933). ${ }^{24}$

In der Kritik standen somit Praktiken (Zeitungslektüre und Kaffeehausbesuch), die die gesellschaftlichen Grenzen einebneten. Auch die Theatralisierung der Gesellschaft und die Dekorationsmanie des Jugendstils wurden mit der moralischen Degeneration in Zusammenhang gebracht. Dabei entbehrt es nicht einer gewissen Ironie, dass Schaukals frühe Dichtung dem literarischen Ornament verpflichtet war und seine Beiträge in ebenjenen Publikationsorganen erschienen, die wegen der Entwicklung des Rotationsdrucks auch in Wien einen

21 Vgl. Osterhammel: Die Verwandlung der Welt, S. 1120.

22 Bourdieu: Die feinen Unterschiede, S. 361.

23 Anton Kuh: Wien ohne Zeitung. In: Kuh: Zeitgeist im Literatur-Café. Feuilletons, Essays und Publizistik. Neue Sammlung. Hg. von Ulrike Lehner. Wien/München 1983, S. 26-29, hier S. 28.

24 Edmund Wengraf: Kaffeehaus und Literatur. In: Die Wiener Moderne. Literatur, Kunst und Musik zwischen 1890 und 1910 Hg. von Gotthart Wunberg. Stuttgart 2006, S. 638-642, hier S. 639 . 
Schub erfahren hatten. Er veröffentlichte Gedichte in den von Jugendstilmalern und -graphikern reich illustrierten Blättern Ver Sacrum, Pan, Jugend und Die Insel. Heinrich Vogeler (1872-1942), Maler der ersten Generation der Künstlerkolonie Worpswede, verzierte Schaukals Buch Pierrot und Colombine (1902). Mit ihm sowie mit den Malern Carl Moll (1861-1945) und Maximilian Liebenwein (1869-1926) führte er ausgedehnte Korrespondenzen. Als Beamter und homme de lettres profitierte Schaukal also von der Technisierung und einer beschleunigten Kommunikation weit über Wien hinaus.

Man kann sich diesbezüglich Richard Schaukals soziale Welt als ein äußerst produktives Kommunikationsdispositiv vorstellen, das im Zuge wachsender Literarisierung einen umfangreichen Resonanz-Raum erzeugte. In diesem wurden soziale, politische, kulturelle und vor allem ästhetische Themen verhandelt; der Raum war als elitäre, die triviale Literarisierung negierende Sphäre konzipiert. Wie wichtig Schaukal Lesen, Schreiben, das Verschicken, Sammeln und Speichern von Schrift war, offenbart sich nicht zuletzt in der Flut seiner Korrespondenzen. „Denn Lesen ist ja außer Schreiben mein ,Lebenszweck““, so Schaukal Mitte der 1930er Jahre an Alfred Kubin (1877-1959). ${ }^{25}$

Die „kommunikative Leidenschaft“ des frühen Bürgertums, die auf einem neuen Transportsystem gründete, ${ }^{26}$ kehrte in seiner Briefkultur und Sammelpraxis als Reflex einer Klasse wieder, der Schaukal eigentlich zu entweichen suchte. Die Lektüre und das Verfassen, Empfangen und Senden von Briefen, Postkarten, Telegrammen und Billets beanspruchte viel Lebenszeit, wie anhand der umfangreichen Hinterlassenschaft ersichtlich ist; mit Rückgriff auf Bourdieu lässt sich behaupten, das beständig wachsende Schriftgut erzeugte, beeinflusste und festigte Schaukals ureigentlichstes „Dispositionssystem“. ${ }^{27}$ Die fortwährenden postalischen Sendungen wurden zu wesentlichen Bestandteilen und Zeugnissen der inkorporierten und objektivierten Merkmale (Habitus und Besitz), in seinem Fall vor allem Immobilien, Bücher und Gemälde. Fotoaufnahmen aus Schaukals Biedermeiervilla in Grinzing belegen jene objektivierten Lebensgewohnheiten des Schriftstellers und seiner Familie, ein Ineinanderfließen von ausgestelltem und gelebtem Bildungskapital, das zugleich soziale Selbstverortung war. Nahezu jeder Raum der Villa war angefüllt mit Büchern bis unter die Decke, mit dunklen Möbeln und Kopien bedeutender Gemälde von

25 Brief Schaukals an Kubin, 19. März 1935, Sammlung Alfred Kubin, Bayerische Staatsbibliothek München (im Folgenden zit. als K-S, BSB).

26 Kaschuba: Die Überwindung der Distanz, S. 43.

27 Bourdieu: Die feinen Unterschiede, S. 25. 
Velázquez' (1599-1660) Infanten-Portrait bis Giorgiones (1478-1510) Die drei Philosophen, das über dem Schreibtisch im Büro angebracht war. ${ }^{28}$

Über das Sammeln, Rezipieren und Verschriftlichen in jeglicher Form - literarisch wie amtlich, privat wie öffentlich - definierte sich der dichtende Beamte. Das mag mit Blick auf Ausbildungsgrad und soziale Herkunft des Kaufmannssohnes plausibel erscheinen. Lesen und Schreiben dienten dem Jungdichter zur Einübung der Codes einer dominierenden Klasse, die kennerhaft über ,legitime Kunst' debattierte. Um Zugang zu den selbstberufenen Bewahrern dieser Kunstauffassung zu erhalten, bedurfte es des Wissens um diskursive Umgangsformen, eines gehobenen Soziolekts, mithilfe dessen ästhetische Themen und günstige Positionen im Sozialraum verhandelt werden konnten. Schaukal war darum bemüht, mit pointierten Geschmacksurteilen den sozialen Aufstieg nach außen zu verkörpern. $^{29}$

Es ist dabei bezeichnend, dass er in der ersten Hälfte seiner über 50 Jahre andauernden schriftstellerischen Tätigkeit insgesamt mehr publizierte - dabei häufiger Gedichte und Prosa - als in der zweiten Hälfte, wollte er sich doch insbesondere in jungen Jahren im kulturellen Feld als ,Aufstrebender' gegenüber den ,Etablierten“ behaupten. Die Lyrik und ihre hermetische Wirkung, die sich dem direkten Verständnis entziehen und mithilfe einer überkommenen Gattungshierarchie zum sozialen Distinktionsmerkmal erheben kann, stellte für Schaukals Ansprüche die ideale Form dar. Sie war auch die einzige, der er sein Leben lang treu blieb.

1918, also gegen Mitte seiner literarischen Karriere, erfolgte die Erhebung in den Adelsstand durch Kaiser Karl I. (1887-1922), in dem er jedoch nur mehr für wenige Monate offiziell verbleiben konnte. Mit dem Ende der Monarchie quittierte Schaukal den Staatsdienst, inskribierte sich in Deutscher und Romanischer Philologie an der Universität Wien und widmete sich seiner nicht sehr lukrativen Tätigkeit als Dichter und Kritiker.

Mit Blick auf die wechselseitige Durchdringung von technischen Neuerungen, gesellschaftlichen Veränderungen, Selbstentwürfen in und mittels traditioneller sowie sich neu etablierender Kulturpraktiken lässt sich das Netz als Metapher heranziehen, um die Vielbezüglichkeit der Moderne zu charakterisieren. Schaukal verfügte über ein weitverzweigtes, dynamisches Netzwerk. ${ }^{30} \mathrm{Zu}$ seinen zahlreichen

28 Diesen Hinweis verdanke ich Claudia Girardi, geb. Warum.

29 Vgl. Bourdieu: Die feinen Unterschiede, S. 18-19; zu Schaukals Geistesadel vgl. Girardi: Der Dichter Richard von Schaukal als „Konservator“ der guten alten Zeit, S. 288-289.

30 Das von der Wienbibliothek im Rathaus angefertigte Nachlass-Verzeichnis listet über 900 Personen, mit denen er schriftlich verkehrte; vgl. Nachlass Richard von Schaukal: ZPH 846. http://share.obvsg.at/wbr02/LQH0000768-1201.pdf (zuletzt aufgerufen am 31. Juli 2019). 
Korrespondenzpartnern zählten bedeutende Politiker ${ }^{31}$ und anerkannte Forscher, ${ }^{32}$ auch aus den Natur- und Geisteswissenschaften. ${ }^{33}$ Zudem befanden sich darunter erfolgreiche Unternehmer, ${ }^{34}$ Schauspielerinnen und Schauspieler, ${ }^{35}$ Tänzerinnen, ${ }^{36}$ eine Vielzahl bildender Künstler ${ }^{37}$ und Komponisten, antisemitische und völkische Dichter, ${ }^{38}$ aber auch Literaten, die später aufgrund ihrer jüdischen Wurzeln emigrieren mussten ${ }^{39}$ oder von den Nationalsozialisten verfolgt, ${ }^{40}$ in Konzentrationslager deportiert und dort ermordet wurden. ${ }^{41}$ Schaukal korrespondierte mit NSDAP-Mitgliedern, ${ }^{42}$ mit Pazifisten, ${ }^{43}$ Antisemitismuskritikern, ${ }^{44}$ Hitler-Gegnern, ${ }^{45}$ mit Journalisten, ${ }^{46}$ Aktivisten, ${ }^{47}$ Verlegern ${ }^{48}$ und mit (unbekannten wie auch weltbekannten) Schriftstellern. Von den über 900 Kontakten, die sein Nachlass verzeichnet, waren circa 300 Dichterinnen und Dichter. ${ }^{49}$

31 Zum Beispiel mit dem österreichischen Politiker und Ministerpräsidenten Max Wladimir Beck (1854-1943), dem Politiker Franz Klein (1854-1926) und mit dem Wegbereiter des austrofaschistischen Ständestaates und Bundeskanzler Ignaz Seipel (1876-1928).

32 Mit dem preußischen Mediziner Ignaz Hirsch (1834-1910).

33 Mit dem Techniker und Forstwissenschaftler Wilhelm Exner (1840-1931).

34 Die Industriellenfamilie Gomperz aus Brünn und Josef von Manner (1865-1947).

35 Raoul Aslan (1886-1958), der auch Burgtheaterdirektor war, und mit dem Schauspieler und Schriftsteller Ferdinand Gregori (1870-1928).

36 Kitty Starling.

37 Etwa Anton Kolig (1886-1950) und Heinrich Vogeler (1872-1942).

38 Unter anderem Adolf Bartels (1862-1945), Sebastian Brunner (1814-1893) und Heinrich Burhenne (1892-1945).

39 Martin Beradt (1881-1949) und Richard Flatter (1891-1960).

40 Ida Dehmel (1870-1942).

41 In Auschwitz ermordete Briefpartner waren der Journalist Hermann Bessemer (1883-1943), der Schriftsteller, Architekt und Loos-Mitarbeiter Alfred Grünewald (1884-1942) sowie der Schriftsteller und Unternehmer Karl Schloß (1876-1944); Josef Bick (1880-1952) überlebte die Haft im Konzentrationslager Dachau; zu den in Theresienstadt ermordeten Künstlern, mit denen Schaukal korrespondiert hatte, gehören Otto Eisenschitz (1863-1942), Gustav Hochstetter (1873-1944), Heinrich Rauchinger (1958-1942), der Literaturhistoriker Alfred Rosenbaum (1861-1942) und der Autor Oskar Wiener (1873-1944).

42 Unter anderem Carl von Barldorff (1865-1953), Benno Geiger (1882-1965), Artur Kutscher (1878-1960) und Wilhelm von Scholz (1874-1969).

43 Anette Kolb (1870-1967) und Ernst Thrasolt (1878-1945).

44 Friedrich von Oppeln-Bronikowski (1873-1936).

45 Elisabeth Darapsky (1913-1998), Walter Ferber (1907-1996).

46 Alfred Gold (1874-1958).

47 Zum Beispiel mit Peter Hamecher (1879-1938) und der Frauenrechtlerin Margarethe Rohrer (auch Margarethe Maria Magdalena Leopoldine Stöger-Steiner Edle von Steinstätten, 1893-1969).

48 Zum Beispiel mit Herwarth Walden (1878-1941).

49 Recherche und Zählung des Verfassers. 
Vor der Analyse der Netzwerke sollen im ersten, biographietheoretischen Teil der Untersuchung Richard Schaukals Strategien der Subjektivierung und Selbstpositionierung erörtert werden. Dabei rücken vor allem sein Verhältnis zur Fotografie und die Aneignung des biographischen Genres als Mittel der Selbstinszenierung in den Analysefokus.

Mit Bezug auf die Netzwerkforschung und Bourdieus Sozioanalyse widmet sich die Studie im zweiten Teil der Frage, welche Möglichkeiten Schaukal zur Verfügung standen, um sich in den literarischen Feldern und Netzwerken der Moderne gewinnbringend $\mathrm{zu}$ positionieren. In diesem Zusammenhang wird untersucht, welche Gesten, Posen, Diskurse und Narrative, etwa des literarischen Gelingens und Scheiterns, in den Korrespondenzen zirkulierten, welche Machtansprüche und Vormachtstellungen im Austausch mit anderen Schriftstellern verbalisiert, eingenommen oder verfehlt wurden und welche Kontakte zu Schaukals ökonomischem Erfolg oder Misserfolg im kulturellen Feld beigetragen haben. Habitus und Kapitalsorten werden als biographische Kategorien adaptiert, um innere Prozesse und äußere Umstände zirkulär in ein biographisches Gesamtbild einzuschließen.

Bis etwa 1905 positionierte sich Schaukal als Verfechter einer zweckfreien Kunst. Demnach hätten kommerzielle Ziele - etwa Verlagshonorare - von geringem Belang sein müssen. Mit Bourdieu gesprochen erfolgt die „Legitimierung sozialer Unterschiede“, auf die auch Schaukal abzielte, einerseits über die Negation „niederer, grober, vulgärer“ Populärkultur und andererseits über die Adaption zweckfreier Kunst. ${ }^{50}$ Doch funktionierte dieses Entgegenlaufen von ästhetischen und ökonomischen Ansprüchen für Schaukal und sein Agieren im kulturellen Feld? Ist, wie Bourdieu zudem behauptet, die ästhetische Einstellung stets von den materiellen Existenzbedingungen abhängig und der Erwerb von kulturellem Kapital „nur um den Preis gleichsam eines Rückzugs aus der Sphäre der ökonomischen Notwendigkeit möglich“? ${ }^{51}$ Und über welchen Aktionsradius verfügte ein Akteur wie Schaukal, der sich in homogenen Sozialstrukturen bewegte? Konnten Gruppenidentitäten über postalische Diskurse gestiftet werden? Welche besonderen Formen der Interaktion, Intertextualität und Intersubjektivität traten gerade in Künstlerzirkeln auf? Diese Reflexionen berühren eine zentrale Frage sowohl der um 1900 wirkenden Literaten als auch der gegenwärtigen Biographiewissenschaft: Wie kann das Ineinandergreifen von Umwelt, Kunst und Leben beziehungsweise

50 Bourdieu: Die feinen Unterschiede, S. 27.

51 Bourdieu: Die feinen Unterschiede, S. 100. 
von äußeren Einflüssen und individuellen Handlungen in eine biographische Darstellungsform übersetzt werden?

\section{Biographie: Gattung und Theorie am Beispiel Richard Schaukals}

Während in den englischsprachigen Ländern die Biographie nicht nur als literarische Gattung, sondern Biographik auch als Theorie weitestgehend anerkannt und vielerorts institutionalisiert ist, ${ }^{52}$ bemängelt vor allem die Literaturund Geschichtswissenschaft im deutschen Sprachraum ein Theoriedefizit für Lebensdarstellungen. ${ }^{53}$

Debatten über die wissenschaftliche Wertigkeit und gesellschaftliche Relevanz von Biographien erstrecken sich über das gesamte 20. Jahrhundert und reichen bis in die Gegenwart. In den 1970er und 1980er Jahren wurde der Gattung vorgehalten, sie habe als metaphysisch aufgeladene Monumentalbiographie ihr geistiges „Existenzrecht“ eingebüßt und könne nur aufgrund „verlegerischer Kalküle“ überleben, ${ }^{54}$ so Carl Dahlhaus, der sich circa ein Jahrzehnt später mit Ludwig van Beethoven und seine Zeit selbst an die biographische Gattung wagte. ${ }^{55}$ Andererseits wurden in den Sozial- und Geschichtswissenschaften innovative biographietheoretische Methoden entwickelt und literarische Texte verfasst, die neue biographische Zugänge erprobten. In jüngerer Zeit widmeten sich zunehmend auch im deutschsprachigen Raum avancierte Projekte, Publikationen und Institute der Erschließung biographischer Formate und Theorien;

52 James Clifford bezeichnet die Biographie als "that most Anglo-Saxon of literary forms“: „Hanging Up Looking Glasses at Odd Corners“: Ethnobiographical Prospects. In: Studies in Biography. Hg. von Daniel Aaron. Cambridge (Mass.)/London 1978, S. 41-56, hier S. 43. David Ellis sieht die Biographie als Bindeglied zwischen Academia und einem interessierten Laienpublikum: Literary Lives. Biography and the Search for Understanding. Edinburgh 2000, S. 1. Vgl. dazu auch Sigrid Löffler: Biografie. Ein Spiel. Warum die Engländer Weltmeister in einem so populären wie verrufenen Genre sind. In: Literaturen, H. 7-8/2001 (Juli/August 2001), S. 14-17.

53 Vgl. Christian Klein: Einleitung: Biographik zwischen Theorie und Praxis. Versuch einer Bestandsaufnahme. In: Grundlagen der Biographik. Theorie und Praxis des biographischen Schreibens. Hg. von Christian Klein. Stuttgart/Weimar 2002, S. 1-22, hier S. 16, sowie Bernhard Fetz: Die vielen Leben der Biographie. In: Die Biographie - Zur Grundlegung ihrer Theorie. Hg. von Bernhard Fetz. Berlin/New York 2009, S. 3-66, hier S. 3.

54 Carl Dahlhaus: Wozu noch Biographien? In: Melos. Neue Zeitschrift für Musik, 1. Jg. (1975), S. 82.

55 Carl Dahlhaus: Ludwig van Beethoven und seine Zeit. Regensburg 1987. 
dennoch konstatieren Wissenschaftlerinnen wie Helga Schwalm: „Eine Theorie der Biographie fehlt bis heute. “56 Dass sich wenig daran geändert hat, legt die Einleitung des 2017 publizierten Sammelbands Biography in Theory nahe. ${ }^{57}$

Die Biographie verfüge nur in Verbindung mit anderen Disziplinen oder Theorien über methodische Relevanz, zum Beispiel mit den Geschichtswissenschaften oder der Erzähltheorie, so ein kritischer Tenor. ${ }^{58}$ Positiv gewendet lässt sich Biographik als interdisziplinäre Schnittstelle unterschiedlicher Theoriefelder bezeichnen: „Die theoretischen Implikationen der Biographie“ erheben sie zum Forschungsobjekt, „in dem sich zentrale Fragen der gegenwärtigen Kulturwissenschaften bündeln.“59

Die biographische Auseinandersetzung kann dabei auch Forschungslücken und verborgene Gesellschaftsphänomene sichtbar machen. Ernst Peter Fischer kritisierte vor wenigen Jahren, dass kaum Biographien über deutschsprachige Wissenschaftler auf Deutsch vorliegen, sehr wohl aber auf Englisch. Der Wissenschaftshistoriker beklagt die mangelnde Bereitschaft zur biographischen Würdigung und Anerkennung deutscher Naturwissenschaftler im deutschen Sprachraum, plädiert dabei aber für einen konventionellen, didaktischen Zugang zum Leben bedeutender Persönlichkeiten, ${ }^{60}$ für eine Verbindung von Person und Werk, die auf Wilhelm Diltheys (1833-1911) Diktum vom Menschen als

56 Helga Schwalm: Biographie. In: Metzler Lexikon Literatur. Hg. von Peter Burdorf u. a. Stuttgart/Weimar 2007, S. 89-91, hier S. 90.

57 Vgl. Edward Saunders: Introduction: Theory of Biography or Biography of Theory? In: Biography in Theory. Key Texts with Commentaries. Hg. von Wilhelm Hemecker und Edward Saunders. Berlin/Boston 2017, S. 1-8.

58 Vgl. Hans Renders und Binne de Haan: Introduction: The Challenges of Biography Studies. In: Theoretical Discussions of Biography. Approaches from History, Microhistory, and Life Writing. Hg. von Hans Renders und Binne de Haan. Lewiston (NY) u. a. 2013, S. 1-12, hier S. 1, sowie Nigel Hamilton: Foreword. In: Theoretical Discussions of Biography, S. i-v, hier S. ii. Die Diskussionen rund um den Theoriemangel der Biographie sind wesentlicher Bestandteil der biographietheoretischen Forschung, wie Christian Klein darlegt, vgl. Klein: Einleitung. Biographik zwischen Theorie und Praxis, S. 1-2. Hans Erich Bödeker erklärte kurz darauf die Zeit für beendet, in der „die Biographie als methodisch unkritisch und theoretisch harmlos abqualifiziert wurde“; Bödeker: Biographie. Annäherungen an den gegenwärtigen Forschungs- und Diskussionsstand. In: Biographie schreiben. Hg. von Hans Erich Bödeker. Göttingen 2003, S. 9-63, hier S. 12.

59 Fetz: Die vielen Leben der Biographie, S. 6.

60 Vgl. Ernst Peter Fischer: Zeigt uns die Pioniere! In: Die Zeit, Nr. 6/2016 (4. Februar 2016). http://www.zeit.de/2016/06/forscherbiografien-deutschland (zuletzt aufgerufen am 31. Juli 2019). 
„Urtatsache aller Geschichte“ rekurriert. ${ }^{61}$ Es besteht nach wie vor eine Diskrepanz zwischen dem Anspruch wissenschaftlicher Biographien und der publikumswirksamen Umsetzung. Fischers Einwand redet dabei der Panegyrik und indirekt auch dem Argument das Wort, der Wert von Biographien ließe sich an Verkaufszahlen messen. In seinem in der Zeit veröffentlichten Artikel fordert er eine Rückkehr zur Individualbiographik. Allerdings hat Christoph Gradmann schon 2003 gerade mit Blick auf Wissenschaftlerbiographien angemerkt, dass

bei der historischen Rekonstruktion medizinischer Forschung ein individualbiographischer Ansatz nicht selten in die Irre [führt]: Der Versuch festzustellen, wer wann und wo eine bestimmte Impftechnik erfunden hat, führt [. . . ] in ein komplexes Geflecht personaler oder institutioneller Akteure, kultureller Praktiken usw. ${ }^{62}$

Die Schwierigkeiten biographischer Forschung gehen unter anderem auch auf begriffliche Unschärfen zurück. Falko Schnicke konstatiert im Handbuch Biographie, dass der Terminus ,Biographie‘ eine Vielzahl miteinander verwandter und konkurrierender Unternehmungen umfasse. Eine detaillierte, differenzierende Studie liegt bislang nicht vor, und so sind ,Lebensbeschreibung،, ,Vita', ,Porträt‘, ,Charakteristik‘, ,Denkmal‘, ,Nekrolog' semantisch erst noch genauer zu unterscheiden. ${ }^{63}$

,Biographie' meint an dieser Stelle ganz allgemein die mediale Darstellung von Leben in unterschiedlichen sozialen wie historischen Zusammenhängen. Ein eigenes Genre stellt die ,Autobiographie، dar. Sie ist allerdings nicht immer eindeutig von der Biographie abzugrenzen, wie auch das Kapitel über Schaukals biographische und selbstbiographische Schriften zeigt. Um für die beiden Gattungen eine einheitliche Bezeichnung zu etablieren, wird vor allem im anglophonen Kontext auf den Begriff ,Life Writing“ zurückgegriffen, der sich zum Teil auch in der deutschsprachigen Biographieforschung etabliert hat. ,Life Writing‘ ist eine direkte Übertragung aus dem Altgriechischen (bios und graphia) und bezieht sich auf eine Vielzahl auto-/biographischer Genres und Gattungen, aber auch auf Materialien und Ego-Dokumente wie ,Tagebuch', ,Memoiren' und ,Briefe‘. Der Begriff geht auf das 18. Jahrhundert zurück, doch hat Virginia

61 Zit. nach Christoph Gradmann: Nur Helden in weißen Kitteln? Anmerkungen zur medizinhistorischen Biographik in Deutschland. In: Biographie schreiben, S. 243-284, hier S. 252.

62 Gradmann: Nur Helden in weißen Kitteln? S. 246.

63 Vgl. Falko Schnicke: Begriffsgeschichte: Biographie und verwandte Termini. In: Handbuch Biographie. Methoden, Traditionen, Theorien. Hg. von Christian Klein. Stuttgart/Weimar 2009, S. 1-6. 
Woolfs (1882-1941) A Sketch of the Past (1939) wesentlich zu seiner Durchsetzung beigetragen. ${ }^{64}$

Während ,Life Writing“ hier nicht verwendet wird, stehen ,Lebensdarstellung‘, ,Lebensbeschreibung‘ oder ,Lebensschilderung“ als Synonyme für ,Biographie‘. Die Begriffe ,Lebensgeschichte‘ und ,Lebenserzählung‘ vermitteln die Vorstellung von linearen, sogar kausal-logischen Abläufen oder kontinuierlichen Entwicklungen eines Lebens und werden daher vermieden. Die vorliegende Untersuchung verzichtet ebenso auf den soziologischen Terminus ,Lebens(ver)lauf‘. Dieser ist insofern irreführend, als er Entwicklungen suggeriert und auf Rudimente des Dreistufenmodells idealtypischer bürgerlicher Lebensläufe zurückgreift, nämlich Ausbildung, eine lange Phase des Erwerbslebens und die abschließende Ruhephase. Während spätestens die moderne Erzählliteratur dieses teleologische Modell verabschieden konnte, tragen konventionelle Biographien oft noch das Etikett ,Entwicklung', eine Vorstellung von fortschreitender und zielgerichteter Zeitlichkeit. ${ }^{65}$

Der ,Lebenslauf' hat Anfang und Ende sowie dazwischen liegende, anhand des Alters bestimmbare und kulturell festgelegte Phasen, also Kindheit, Jugend, Erwachsenenalter. Avancierte Biographien gehen über diese Strukturierung hinaus und beziehen etwa auch die Vorgeschichte, das Nachleben oder die Perspektive des Biographen mit ein, um übergeordnete Zusammenhänge abzubilden. Diese Biographien richten (im wissenschaftlichen Idealfall) ihren Blick auf gesellschaftliche wie literarische Konstruktionen und reflektieren strukturelle Prozesse und Mechanismen, die zu einer bestimmten Vorstellung von Leben und einer möglichen biographischen Version führen. Während „Lebenslauf“ also die zeitlich messbare „Evidenz“ darstellt, verweist die Biographie auch auf die „Konstruktion“ von Lebensläufen, so Bernhard Fetz: „Die beiden Seiten zusammenzudenken, trifft den heißen Kern jeglicher Theorie der Biographie.“66

Die vorliegende Studie verwendet ,Lebenslauf‘ entsprechend den Ausführungen Pierre Bourdieus. Der Soziologe meint damit die nicht zielgerichteten und nicht linear verlaufenden, individuellen Möglichkeiten für Positionenwechsel von Akteuren innerhalb der Felder im sozialen Raum. ${ }^{67}$ Dieser Blickwinkel betrachtet Leben nicht als chronologischen Ablauf, sondern die Akteure je nach ihrer Position in der sozialen Welt.

64 Vgl. Zachary Leader: Introduction. In: On Life-Writing. Hg. von Zachary Leader. Oxford 2015, S. 1-6, hier S. 1. Außerdem Manfred Mittermayer: Die Autobiographie im Kontext der ,Life-Writing'-Genres. In: Die Biographie - Zur Grundlegung ihrer Theorie, S. 69-101.

65 Vgl. Fetz: Die vielen Leben der Biographie, S. 18.

66 Fetz: Die vielen Leben der Biographie, S. 51-53

67 Vgl. Bourdieu: Die feinen Unterschiede, S. 188-189. 
Biographietheorie und Biographik bezeichnen die theoretischen Perspektiven, Aspekte und Methoden biographischer Texte und ihrer wissenschaftlichen Darstellungsformen. Dazu gehört auch die Entwicklung von ,Subkulturen', die Themen und Narrative abseits konventioneller Lebensdarstellungen in den Blick nehmen. Subjektive Biographie, Anti-Biographie oder Gegenbiographie sind Ergebnisse kritischer Auseinandersetzungen mit dem Thema. Wilhelm Hemecker bemerkt einen zunehmend produktiven Widerstand gegen die Gattung, der sich in Form von , antibiographischen' Biographien äußert und für den Autoren wie David Edwin Nye stehen. ${ }^{68}$ Der Strukturhistoriker verfasste 1983 eine antibiographisch ausgerichtete Studie über Thomas Edison (1847-1931). ${ }^{69}$ Sein diskursanalytischer Ansatz, Personen als Symbole zu untersuchen und die Untersuchung an die Aussagemöglichkeiten von Dokumenten zu knüpfen, setzte wesentliche biographietheoretische Impulse. Nye erklärt sein biographisches Experiment folgendermaßen: „Statt zu versuchen, Edison zu fixieren, entschied ich mich dafür, ihn als Bündel von Möglichkeiten zu betrachten. “70 Während Robert Musil den ,Möglichkeitssinn“ als logische Konsequenz und Widerpart eines um 1930 noch kaum bezweifelten ,Wirklichkeitssinns‘ literarisch reflektierte, haben sich ein halbes Jahrhundert später die Vorzeichen umgekehrt. Nye und Bourdieu belegen, wie sich in den Geisteswissenschaften eine Auffassung entwickelte, die Musil im Mann ohne Eigenschaften ironisch vorweggenommen hatte:

\footnotetext{
Wer ihn [den Möglichkeitssinn] besitzt, sagt beispielsweise nicht: Hier ist dies oder das geschehen, wird geschehen, muß geschehen; sondern er erfindet: Hier könnte, sollte oder müßte geschehen; und wenn man ihm von irgend etwas erklärt, daß es so sei, wie es sei, dann denkt er: Nun, es könnte wahrscheinlich auch anders sein. So ließe sich der Möglichkeitssinn geradezu als die Fähigkeit definieren, alles, was ebensogut sein könnte, zu denken und das, was ist, nicht wichtiger zu nehmen als das, was nicht ist. ${ }^{71}$
}

68 Vgl. Wilhelm Hemecker: Einleitung. Ingeborg Bachmann zwischen Mythos und Metabiographik. In: Mythos Bachmann. Zwischen Inszenierung und Selbstinszenierung. Hg. von Wilhelm Hemecker und Manfred Mittermayer. Wien 2011, S. 7-16, hier S. 7.

69 David Edwin Nye: The Invented Self: An Anti-Biography, from Documents of Thomas A. Edison. Odense 1983.

70 David Edwin Nye: Nach Thomas Edison. Rückblick auf eine Anti-Biographie [2003]. In: Theorie der Biographie. Grundlagentexte und Kommentar. Hg. von Bernhard Fetz und Wilhelm Hemecker. Berlin/New York 2011, S. 347-360, hier S. 353.

71 Robert Musil: Der Mann ohne Eigenschaften, S. 20. 
Musil steht in einer Reihe mit Schriftstellern, Philosophen und Gesellschaftstheoretikern, die sich zu Beginn des 20. Jahrhunderts „mit der ,versuchsweisen“ Erforschung von Noch-Nicht-Gewusstem“ beschäftigt „und dabei die intellektuellen, kulturellen, politischen und wissenschaftlichen Begrenzungen ihrer Disziplinen" überschritten haben. ${ }^{72}$

Vor allem die biographischen Dokumente spielen eine wesentliche Rolle für den Prozess, Leben entsprechend seiner vielen Möglichkeiten darzustellen. Die Widersprüchlichkeiten der Dokumente über Edison veranlassten Nye zu einer biographischen Erkenntniskritik. Chronologie und Entwicklungsgestus, die klassische Biographien zumeist prägen, unterläuft Nye, indem er eine begrenzte Zahl von Berichten und die darin enthaltenen Kontradiktionen diskursanalytisch gegenüberstellt. Dadurch werden biographische Inszenierungen ersichtlich, die einen einheitlichen Subjektbegriff obsolet werden lassen; abgesehen von den von Edison gesetzten Selbstentwürfen, zählt Nye acht unterschiedliche EdisonFiguren, also unterschiedliche Subjektivierungen der Person namens Edison, die zwischen 1870 und 1880 von der Presse modelliert wurden. ${ }^{73}$

Zehn Jahre vor Nyes Studie hatte bereits Roland Barthes den geschlossenen Autorbegriff kritisch reflektiert: „Der aus seinem Text heraus- und in unser Leben eintretende Autor ist keine Einheit“, so Barthes, „er ist für uns ganz einfach eine Vielzahl von ,Reizen“, der Ort einiger zerbrechlicher Details und doch Quelle lebendiger romanesker Ausstrahlungen.“ „Die Lust am Text“ führe zu einer „freundschaftlichen Wiederkehr des Autors.““74 Barthes erhebt das Fragment zur neuen, unkonventionellen und lustvollen Möglichkeit biographischer Erschließungen. Er bezeichnet diese Splitter oder Teile eines Lebens, die in keiner Relation oder Chronologie zueinander zu stehen brauchen, ,Biographeme‘. Auch Michel Shortland und Richard Yeo legen in ihren Studien den Fokus auf die Vielschichtigkeit der Biographien. Personen sollen ,dezentriert' positioniert und nur jene Teilprozesse in den Blick genommen werden, die zu unterschiedlichen Subjektivierungsformen beitragen. ${ }^{75}$

72 Roland Innerhofer und Katja Rothe: Das Mögliche regieren. Einleitung. In: Das Mögliche regieren. Gouvernementalität in der Literatur- und Kulturanalyse. Hg. von Roland Innerhofer, Katja Rothe und Karin Harrasser. Bielefeld 2011, S. 9-18, hier S. 11.

73 Vgl. Nye: Nach Thomas Edison, S. 350.

74 Roland Barthes: Sade, Fourier, Loyola [1971]. Aus dem Franz. von Maren Sell und Jürgen Hoch. Frankfurt am Main 1974, S. 12.

75 Vgl. Michael Shortland und Richard Yeo: Introduction. In: Telling Lives in Science. Essays on Scientific Biography. Hg. von Michael Shortland und Richard Yeo. New York 1996, S. 1-44. 
$\mathrm{Zu}$ den Kritikpunkten der biographietheoretischen Debatten zählten in der zweiten Hälfte des 20. Jahrhunderts der illusorische Aspekt von Biographien und die Flüchtigkeit ihrer Protagonisten. Lebensgeschichten suggerieren Wahrheit und können den von ihnen aufgestellten Objektivitätsanspruch nicht einlösen. Die Gretchenfrage der Biographieforschung lautet bis heute, ob sie generell über wissenschaftliches Potential verfüge. Die Lust am Aufdecken und Eindringen in die Privatsphäre erhebt die Biographie zum beliebten Verkaufsund Leseprodukt, aus wissenschaftlicher Perspektive wird sie aber immer wieder als unseriöse Gattung bezeichnet. Die große Zahl jährlich publizierter Lebensdarstellungen scheint die theoretische Infragestellung der Biographie zu unterlaufen. Doch ist, wie bei anderen Gattungen auch, zwischen trivialen, populärbiographischen Werken zu unterscheiden, die auch Gegenstand der Biographieforschung sein können, und wissenschaftlich ambitionierten Projekten.

Stellt sich ein biographisches Vorhaben wissenschaftlichen Ansprüchen, eröffnen sich unkonventionelle methodische Wege und Sackgassen. Neben der Frage nach dem Wahrheitsgehalt von Biographien ist die politische Instrumentalisierbarkeit ein wesentlicher Aspekt, den bereits Helmut Scheuer in seiner ideologiekritischen Monographie zum Thema grundlegend herausgearbeitet hat. ${ }^{76}$ Die biographische Perspektive rückte in der Folge kritischer Biographieforschung von der historischen Persönlichkeit ein Stück weit ab. Biographien nahmen auch Quellen und ihre verborgenen Subtexte in den Blick. Seit dem Ende der 1990er Jahre zeichnet sich in den Geisteswissenschaften gleichzeitig ein Trend zur Evidenz ab, der in aktuellen Diskussionen rund um den neuen Realismus fortgeführt wird. ${ }^{77}$ Der neue Realismus baut zwar auf Konstruktivismus und Poststrukturalismus auf, sieht Wahrheit jedoch nicht als abstrakten Begriff und überlässt die damit verbundenen Diskurse auch nicht den Naturwissenschaften.

76 Vgl. Helmut Scheuer: Biographie. Studien zur Funktion und zum Wandel einer literarischen Gattung vom 18. Jahrhundert bis zur Gegenwart. Stuttgart 1979, vor allem S. 158-166. 77 Vgl. zum Beispiel Manfred Frank: Die Unhintergehbarkeit von Individualität. Reflexionen über Subjekt, Person und Individuum aus Anlaß ihrer ,postmodernen` Toterklärung. Frankfurt am Main 1986; sowie Hans Ulrich Gumbrecht: Die Rückkehr des totgesagten Subjekts. In: Frankfurter Allgemeine Zeitung, 7. Mai 2008, S. N3. Zum Neuen Realismus vgl. Der Neue Realismus. Hg. von Markus Gabriel. Frankfurt am Main 2014; sowie Markus Gabriel: Fünf Jahre Neuer Realismus. Wider die postmoderne Flucht vor den Tatsachen. In: Neue Zürcher Zeitung, 19. Juni 2016. Online: http://www.nzz.ch/feuilleton/fuenf-jahre-neuer-realismus-wider-diepostmoderne-flucht-vor-den-tatsachen-ld.89931 (zuletzt aufgerufen am 31. Juli 2019); außerdem Matthew B. Crawford: Die Wiedergewinnung des Wirklichen. Eine Philosophie des Ichs im Zeitalter der Zerstreuung. Aus dem Amerikan. von Stephan Gebauer. Berlin 2016. 
Für die Biographie stellt sich in diesem Kontext die Frage, wie das Leben und Wirken von Personen wissenschaftlich behandelt und ihre (historische) Präsenz in faktographische Narrative eingebettet werden kann, wenn doch jedes Subjekt zugleich auch der Kreuzungspunkt unterschiedlicher, oft ambivalenter soziokultureller Einflüsse und Diskurse ist. Der Historiker Jacques Le Goff gehört zu den Forschern, die einen methodisch gewinnbringenden Ausgleich zwischen Strukturgeschichte und historischer Biographie proklamieren. Für die Darstellung sozialer Zusammenhänge könne auf Erzählungen zurückgegriffen werden, so Le Goff, wodurch die Biographie eine „phänomenale Wiedergeburt“ erfahren habe. ${ }^{78}$ Als „revival of narration“ bezeichnete Lawrence Stone bereits 1979 die Entwicklung von einer System- zur Subjektperspektive, ${ }^{79}$ und zwei Jahre vor Carlo Ginzburgs mikrogeschichtlicher Erzählung Der Käse und die Würmer (1976) ${ }^{80}$ hatte der Historiker Hayden White eine Untersuchung zu Metahistory veröffentlicht, die Geschichtswissenschaft als Literaturtheorie betrachtet. ${ }^{81}$

Der vermeintliche Tod des Autors und seine Wiederkehr, mit dem neue Impulse für Historiographie, Biographik und Erzähltheorie einhergegangen sind, bezeichnet keine zeitliche Abfolge. Es handelt sich dabei eher um parallel ablaufende Entwicklungen mit unterschiedlichen Zyklen. ${ }^{82}$ Gerade auch mit Blick auf Michel Foucault und Roland Barthes, die oft zitierten Gewährsleute des Autorsterbens, ist von einem Fortleben unter veränderten theoretischen Vorzeichen die Rede. ${ }^{83}$

Parallel zur Subjekt-Depotenzierung und konstruktivistischen DiskursZentrierung entwickelte sich im biographisch-literarischen Umfeld eine ,Neue Subjektivität‘, die den Schreibprozess als Selbsterfahrung in den Mittelpunkt

78 Jacques Le Goff: Wie schreibt man eine Biographie? In: Fernand Braudel u. a.: Der Historiker als Menschenfresser. Über den Beruf des Geschichtsschreibers. Berlin 1990, S. 103-112, hier S. 103.

79 Lawrence Stone: The Revival of Narrative: Reflections on a New Old History. In: Past \& Present, Nr. 85 (1979), S. 3-24.

80 Vgl. Carlo Ginzburg: Il formaggio e i vermi. Il cosmo di un mugnaio del '500. Turin 1976.

81 Vgl. Hayden White: Metahistory: The Historical Imagination in Nineteenth-Century Europe. Baltimore/London 1974.

82 Vgl. Fotis Jannidis u. a. (Hg.): Rückkehr des Autors. Zur Erneuerung eines umstrittenen Begriffs. Berlin 2008 [1999]; außerdem Ansgar Nünning: Von der fiktionalen Biographie zur biographischen Metafiktion. Prolegomena zu einer Theorie, Typologie und Funktionsgeschichte eines hybriden Genres. In: Fakten und Fiktionen. Hg. von Christian von Zimmermann. Tübingen 2000, S. 15-36, besonders S. 15-16.

83 Vgl. vor allem Barthes: Sade, Fourier, Loyola; und Barthes: Die Lust am Text [1973]. Aus dem Franz. von Traugott König. Frankfurt am Main 1974. 
rückte. Wolfgang Hildesheimers (1916-1991) Mozart-Essay, ${ }^{84}$ den der Verfasser weder als Anti-/Biographie noch als Monographie verstanden wissen wollte, ist eine selbstreflexive Lebensbeschreibung, die unter anderem auf Verfahren der Psychoanalyse zurückgreift. ${ }^{85}$ Wie Hildesheimer stellten auch Ingeborg Bachmann (1926-1973), Max Frisch (1911-1991), Uwe Johnson (1934-1984), Christa Wolf (1929-2011) und vor allem Dieter Kühn (1935-2015) den Schreibprozess ins Werk-Zentrum. Literaten und Biographen brachten sich selbst und ihre Methoden dezidiert mit ein, ${ }^{86}$ ohne hinter einen ,althergebrachten Objektivitätsgestus“ zurückzufallen. ${ }^{87}$ Auch in post-postmodernen Zeiten ist demnach „[d]as biographische Erzählen [.. .] nicht schlicht verabschiedet worden, sondern durchlief mehrmals einen Funktionswandel.“88

Dieser Dualität von Tod und Wiedergeburt des Autors und der dargestellten Objekte scheint die Erkenntnis zu entspringen, dass nicht nach der einen biographischen oder strukturgeschichtlichen Wahrheit zu suchen ist, sondern Lebensbeschreibungen und soziohistorische Prozesse miteinander verglichen und in einen sich gegenseitig erhellenden Kontext gestellt werden können. Biographien werden als ,perlokutionäre Akte‘ im Bewusstsein gehalten (John Austin), sie beeinflussen das Nachleben der geschilderten Person und wirken an Kanonisierungsprozessen mit. ${ }^{89}$ Forscher und ihre biographischen Untersuchungsobjekte tragen diskursiv zur Konstruktion eines Lebensbildes bei und antizipieren Ergebnisse. ${ }^{90}$ Doch die Begriffe Evidenz und Erzählung sind für die Biographietheorie deshalb nicht kategorisch auszuschließen, sondern mit konstruktivistischen Erkenntnissen in Beziehung zu setzen.

„Was kann man heute von einem Menschen wissen?“, fragt Jean-Paul Sartre (1905-1980) im Vorwort zu Der Idiot der Familie. ${ }^{91}$ Das bringt die ontologische Kernfrage vieler geisteswissenschaftlicher Disziplinen auf den Punkt. Je höher

84 Vgl. Wolfgang Hildesheimer: Mozart. Frankfurt am Main 1977.

85 Vgl. Hildesheimer: Die Subjektivität des Biographen [1981]. In: Theorie der Biographie, S. 285-295.

86 Beispielsweise ist hier die Biographie Der Orientalist. Auf den Spuren von Essad Bey des amerikanischen Journalisten und Biographen Tom Reiss zu nennen (Berlin 2008). Reiss beschreibt darin seine detektivische Spurensuche und die Offenlegung des Schriftstellerpseudonyms Essad Bey als Lev Nussimbaum.

87 Klein: Einleitung: Biographik zwischen Theorie und Praxis, S. 12.

88 Peter Braun und Bernd Stiegler: Die Lebensgeschichte als kulturelles Muster. Zur Einführung. In: Literatur als Lebensgeschichte. Biographisches Erzählen von der Moderne bis zur Gegenwart. Hg. von Peter Braun und Bernd Stiegler. Bielefeld 2012, S. 9-22, hier S. 11.

89 Vgl. Fetz: Die vielen Leben der Biographie, S. 33.

90 Vgl. Klein: Biographik zwischen Theorie und Praxis, S. 13.

91 Jean-Paul Sartre: Der Idiot der Familie. Reinbek bei Hamburg 1986, S. 7. 
der Reflexionsgrad und je ausgeprägter das methodische Problembewusstsein, desto flüchtiger das biographische Objekt. Im Bewusstsein, dass Forschung einen bestimmten Untersuchungsweg a priori vorgibt und Ergebnisse somit zwangsläufig subjektiven Einflüssen unterstehen, soll hier in Anlehnung an Sartre die Frage abgeändert werden: Welche biographischen Herangehensweisen sind überhaupt möglich, wenn die komplexe Sozialwelt und innere Prozesse zusammen erforscht werden sollen? Welche Selbst- und Fremdentwürfe lassen sich konkret in Schaukals Leben und seinen Kontakten festmachen? Welche Position, welche Rolle nahm er auf welche Weise im sozialen Raum und zu den wichtigsten Akteuren darin ein, und unter welchen Bedingungen führte er seine Handlungen als Beamter, Kritiker, Übersetzer und vor allem als Schriftsteller und Literaturvermittler aus?

Die Biographie stellt eine Möglichkeit unter vielen dar, sich eines Themas methodisch anzunehmen. Aus einer bestimmten Perspektive, mit Rückgriff auf vorhandene Quellen und unter Verwendung von narrativen und technologischen Mitteln wird eine Version der Biographie erzeugt. ${ }^{92}$ Keine Biographie könne jemals das letzte Wort sein, so Nye über seine Edison-Antibiographie. Nicht im Streben nach Letztgültigkeit liegt der biographische Erkenntniswert, sondern in der Veranschaulichung von ganz unterschiedlichen Teilaspekten und ihrer Strukturen sowie Funktionen. ${ }^{93}$

\subsection{Biographiewürdigkeit}

Bis heute folgen konventionelle Biographien oftmals einem wissenschaftlichen, sozialen, kalendarischen oder ökonomischen Konsens darüber, welche Persönlichkeiten oder Leistungen darstellungswürdig sind. Dabei bewegt sich das Interesse am biographischen Objekt oft Parallel $\mathrm{zu}$ erkenntnistheoretischen und gesellschaftspolitischen Bewegungen. Im Zentrum der Auswahl eines biographischen Themas steht die Frage nach bestimmten Funktionsweisen, so zum Beispiel nach der Rolle des ,erzählten“ Lebens für ein kulturelles Gedächtnis und die damit zusammenhängenden Kanonisierungsprozesse. Die Auswahl kann dabei eine Rückbindung an die Biographen darstellen (in Form einer symbolischen Profilierung). Es geht also auch um öffentliche, zumeist indirekt verhandelte Legitimierung und Selbstlegitimierung.

92 Vgl. Christian von Zimmermann: Exemplarische Lebensläufe: Zu den Grundlagen der Biographik. In: Frauenbiographik. Lebensbeschreibungen und Porträts. Hg. von Christian und Nina von Zimmermann. Tübingen 2005, S. 3-16, hier S. 15.

93 Vgl. Nye: Nach Thomas Edison, S. 353. 
Manche der biographischen Funktionsweisen sind über die Jahrhunderte gleich geblieben. Einfühlung und Identifikation mit dem dargestellten Objekt können zwar noch immer als Movens betrachtet werden, Biographien zu lesen und zu schreiben, sie generieren aber kein so wesentliches Gattungsmerkmal mehr wie noch im 18. und 19. Jahrhundert.

Im Prinzip handeln biographische Untersuchungen, die eine fachliche Nähe zur Literaturwissenschaft aufweisen - und auch jene, die sich kollektiv- oder antibiographisch nennen -, vom Bezug eines oder mehrerer Objekte zur Welt. Das beschreibende Subjekt (als Biograph), die beschriebenen Leben und eine Interaktionsfläche (geopolitische oder geschichtliche Hintergründe beziehungsweise der soziale Raum) ergeben eine miteinander in Verbindung gesetzte Trias oder - metaphorisch ausgedrückt - ein in Position und Wertung austauschbares Triptychon. Damit ist gemeint, dass Stellung, Perspektive und thematische Gewichtung unterschiedlich konzipiert sein können. Mal ist es der historische oder strukturelle Rahmen, dann wieder der Bezug des Biographen zum erforschten Objekt oder auch das Material und die (digitalen) Darstellungsmöglichkeiten, die im Zentrum der Betrachtung stehen. Ein konstanter Kristallisationspunkt bleibt dabei die direkt oder indirekt verhandelte Biographiewürdigkeit, die nachhaltig von Thomas Carlyles (1795-1881) und Jacob Burckhardts (1818-1897) problematischem Verständnis von Heldentum und historischer Größe geprägt worden ist.

Die meisten Biographien stellen die Legitimation ihres Untersuchungsobjekts nicht weiter infrage; andererseits kann eine die kulturell geprägte Auffassung von Größe unterlaufende Herangehensweise gerade Forschungsinteresse erzeugen, zum Beispiel in mikrogeschichtlichen oder soziologischen beziehungsweise in feministischen oder postkolonialen Studien.

Grundlegend für die Auswahl bleibt in negativer wie positiver Auffassung das Außergewöhnliche und Untypische einerseits sowie das Alltägliche und Typische andererseits. ${ }^{94}$ Zwischen diesen beiden Perspektiven steht Richard Schaukal. Der umfangreiche Nachlass, die Tatsache, dass die ihn betreffenden Dokumente archiviert wurden, die spezifischen Kontakte, seine zahlreichen dichterischen und essayistischen Publikationen und die breite Rezeption zu Lebzeiten begünstigen Schaukals Biographiewürdigkeit. Doch im Gegensatz zu vielen dichtenden Zeitgenossen ist er am Rande der Literaturgeschichte angesiedelt, keineswegs kanonisiert und der überwiegende Teil seiner Briefwechsel unveröffentlicht. Schaukal gehört jedoch auch nicht zu den gänzlich unbekannten, vergessenen ,infamen Menschen', deren Schicksale Carlo Ginzburg, Natalie Zemon

94 Vgl. Hannes Schweiger: ,Biographiewürdigkeit‘. In: Handbuch Biographie, S. 32-36. 
Davis oder Michel Foucault aus jahrhundertealten Archivbeständen zu neuem Leben erweckt oder in Diskurse eingebettet haben.

Schaukal soll weder ideologisch rehabilitiert noch zum Protagonisten affirmativer Kanondebatten erhoben werden. Es soll auch nicht der Eindruck entstehen, dass gerade er unabdingbar für den hier gewählten theoretischmethodischen Rahmen ist. Ganz im Gegenteil liegt das Interesse auch in seiner Austauschbarkeit, die mit biographisch stark aufgeladenen Namen nicht unbedingt gegeben wäre. Der Blick auf seine Person und das Werk haftet bis heute an einer historisch wie aktuell bedingten Auffassung von mangelnder Größe und - verbunden mit seinem literarischen Schaffen am Beginn der Wiener Moderne - an den Kategorien Innovation und Mediokrität. Kategorien, die vor allem wegen der produktiven Wiederaufnahmen, welche die Literatur der Jahrhundertwende maßgeblich prägten, neu zu reflektieren sind. Schaukals Lebenslauf und sein künstlerisches Schaffen umfassen Singularität und Typik gleichermaßen, seine Person eignet sich für eine Untersuchung, die sowohl das Besondere wie auch das Durchschnittliche zeigt. Er unterläuft jene dichotomische Unterteilung in ,relevant' und ,irrelevant', wie sie bis heute in der Forschung verbreitet, mit einer avancierten biographischen Methode jedoch nicht kompatibel ist. Schaukal repräsentiert das ,außergewöhnlich Typische“, ${ }^{95}$ seine literarischen Erzeugnisse sind Ausdruck der Zeit, und fallen doch auch wieder aus ihr heraus.

\subsection{Forschungsstand zu Richard Schaukal als Ausdruck von Biographiewürdigkeit?}

Das von Ingo Warnke und Andreas Wicke zwischen 1997 und 2002 herausgegebene Jahrbuch der Richard-Schaukal-Gesellschaft Eros Thanatos liefert die nach wie vor aktuellste und eine in vielen Belangen grundlegende Sammlung einzelthematischer Untersuchungen über den Dichter. Das Jahrbuch ist Ausdruck einer in den 1990er Jahren einsetzenden intensiven Auseinandersetzung mit Richard Schaukal.

Die vorliegende Untersuchung knüpft an Einzelanalysen des Jahrbuchs an, die immer wieder auch Schaukals Kontakte zu Exponenten der Jahrhundertwende

95 Der Begriff ,außergewöhnlich Normales‘ oder ,exzeptionell Typisches‘, der für die Umschreibung der mikrogeschichtlichen Methode herangezogen wird, geht auf den italienischen Historiker Edoardo Grendi zurück und lautet im Original ,l'eccezionale normale; vgl. Ida Fazio: Microstoria. http://www.studiculturali.it/dizionario/lemmi/microstoria.html (zuletzt aufgerufen am 31. Juli 2019). 
behandeln. ${ }^{96}$ Auffallend ist, dass diese - mit Ausnahme der Beiträge von Christian Oesterheld und Sybille Leitner - nur den Briefwechsel jeweils zweier Korrespondenzpartner in den Blick nehmen. Der Konnex zu ,bedeutenden' Dichterinnen und Dichtern wird hergestellt, um die biographische oder literaturgeschichtliche Relevanz Schaukals zu legitimieren, so der Eindruck. Dies zeigt sich auch deutlich in Herbert Lehnerts Aufsatz über „Nebenfiguren in der Biographie Thomas Manns“, in dem auch Schaukal erwähnt wird. ${ }^{97}$ Gerade mit Blick auf das Zeitalter der Kreise und Gruppen ist es aber sinnvoll, Schaukals literarische Kontakte und seine Positionen in einem größeren Gefüge zu untersuchen, um das Wirken von Künstlergruppen und Dichterzirkeln netzwerkdynamisch sichtbar machen $\mathrm{zu}$ können. Dabei liefern vor allem die Briefwechsel Hinweise auf die ästhetischen Positionen und die ideologische Gedankenwelt des Dichters. Zu diesem Zweck werden erstmals unveröffentlichte Korrespondenzen aus Schaukals Nachlass herangezogen. Außer den Schriftwechseln mit Marie von Ebner-Eschenbach (1830-1916) und Arthur Schnitzler (1862-1931) liegen lediglich Thomas Manns (1875-1955) Briefe an Schaukal vollständig publiziert vor. ${ }^{98}$

Abgesehen von zwei an der Universität Wien verfassten Dissertationen aus dem Jahr 1948 erschienen circa 20 Jahre nach Schaukals Tod erste Forschungsbeiträge, wobei bis 1990 - also in knapp fünf Jahrzehnten - lediglich 19 zum Teil nicht publizierte Arbeiten unterschiedlicher Länge zu Schaukal entstanden sind. ${ }^{99}$

96 Vgl. Sibylle C. Leitner: Richard von Schaukal und Heinrich Vogeler - Paradigma einer Wechselwirkung der Künste. In: Eros Thanatos. Jahrbuch der Richard-von-SchaukalGesellschaft, Bd. 2 (1998), S. 7-26; sowie Karl Koweindl: „Unser Briefwechsel ist so sehr auf Gefühl und intime Aussprache eingestellt“ - Alfred Kubin und Richard von Schaukal. In: Eros Thanatos, Bd. 2 (1998), S. 27-46. Außerdem Nikola Roßbach: Richard Schaukal und Arthur Schnitzler: Korrespondenzen. In: Eros Thanatos, Bd. 3-4 (1999/2000), S. 27-50; sowie Christian Oesterheld: „Ein Höhenwanderer zur Seelenklarheit“ - Schaukal und der George-Kreis. in: Eros Thanatos, Bd. 3-4 (1999/2000), S. 71-88.

97 Vgl. Herbert Lehnert: Nebenfiguren in der Biographie Thomas Manns. In: Orbis Litterarum, Bd. 63, H. 4 (2008), S. 335-353.

98 Vgl. Claudia Girardi (Hg.): Thomas Mann: Briefe an Richard Schaukal. Frankfurt am Main 2003. Neben der genannten Briefedition und einer dreibändigen Dissertation über Schaukal als Kritiker und Übersetzer aus dem Französischen (1993) veröffentlichte Claudia WarumGirardi unter anderem auch die Briefe von Marie von Ebner-Eschenbach und Richard Schaukal; vgl. Girardi: „Alte Schlösser lieb ich ... “: Mährische Salonkultur am Beginn der literarischen Moderne. Briefe von Marie von Ebner-Eschenbach und Richard Schaukal. In: Beiträge zu Komparatistik und Sozialgeschichte der Literatur. Hg. von Norbert Bachleitner, Alfred Noe und Hans-Gert Roloff. Amsterdam 1997, S. 741-778.

99 Vgl. Ludwig Gernot: Richard Schaukal: Versuch einer Monographie. Diss. Univ. Wien, 1948; Emma Rösner: Die Novellen Richard von Schaukals. Diss. Univ. Wien, 1948; Karl Mayer: Richard Schaukals Weltanschauung. Diss. Univ. Wien, 1959; Robert Mühlher: Ungedruckte 
Allein in den Jahren zwischen 1991 und 2002, dem Erscheinungsjahr des bislang letzten Bandes von Eros Thanatos, wurden 39 Aufsätze zu Schaukal veröffentlicht (davon 21 im Jahrbuch der Schaukal-Gesellschaft). Zwischen 2003 und 2019 ließen sich 21 Beiträge nachweisen. Eine grundlegende, positivistisch ausgerichtete Studie verfasste Dominik Pietzcker, der auch auf Schaukals dichterische Beziehungen zu Rainer Maria Rilke (1875-1926), Hugo von Hofmannsthal (1874-1929), Thomas Mann (1875-1955) und Heinrich Mann (1871-1950) eingeht. ${ }^{100}$ Davor

Briefe Johann Černys an Richard Schaukal. In: Peripherie und Zentrum: Studien zur österreichischen Literatur. Hg. von Gerlinde Weiss und Klaus Zelewitz. Salzburg u. a. 1971, S. 177-194; Robert Mühlher: Hans von Müller (1875-1944). Eine Porträtskizze mit unveröffentlichten Briefen von H. v. Müller an Richard von Schaukal. In: Jahrbuch des Wiener Goethe-Vereins, Bd. 75 (1971), S. 99-128; Maria Maurer: Sprache und Stil in der erzählenden Prosa von Richard von Schaukals. Diss. Univ. Innsbruck, 1971; Karin Plumer: Die autobiographischen Schriften Richard von Schaukals. Hausarbeit an der Univ. Wien 1972; Gustav Kars: 1874. In: Literatur und Kritik, H. 83 (1974), S. 144-161; Rolf E. Windhorst: Richard von Schaukals Begegnung mit der französischen Literatur. In: Sprachkunst, 5. Jg. (1974), S. 244-267; Reinhard Urbach: Leibhaftiges Dilemma der Jahrhundertwende. Bemerkungen zu Richard Schaukal. In: Neue Zürcher Zeitung (26./27. April 1975), S. 57; Reinhard Urbach (Hg.): Richard Schaukal - Arthur Schnitzler: Briefwechsel (1900-1902). In: Modern Austrian Literature: Journal of the International Arthur Schnitzler Research Association, Bd. 8, Nr. 3-4 (1975), S. 15-42; Viktor Suchy: Die „österreichische Idee“ als konservative Staatsidee bei Hugo von Hofmannsthal, Richard von Schaukal und Anton Wildgans. In: Staat und Gesellschaft in der modernen österreichischen Literatur. Hg. Friedbert Aspetsberger. Wien 1977, S. 21-43; Karl Johann Müller: Das Dekadenzproblem in der österreichischen Literatur um die Jahrhundertwende, dargelegt an Texten von Hermann Bahr, Richard von Schaukal, Hugo von Hofmannsthal und Leopold von Andrian. Stuttgart 1977; Steven D. Martinson: Eine Miszelle zu: „Ruine Klamm“. Ein unbekanntes Gedicht von Richard Schaukal. In: Modern Austrian Literature, Bd. 14, Nr. 1-2 (1981), S. 80-83; Enrico de Angelis: Die Poesie als Erfahrung des Minimalen. Zwei Symbolisten. In: Akten des Internationalen Symposiums „Arthur Schnitzler und seine Zeit“. Hg. von Giuseppe Farese. Bern u.a. 1985, S. 225-243; Wilfried Ihrig: Richard von Schaukal, „Leben und Meinungen des Herrn Andreas von Balthesser“. In: Literatur und Kritik, H. 209-210 (1986), S. 471-473; Johann Sonnleitner: Eherne Sonette 1914. Richard von Schaukal und der Erste Weltkrieg. In: Österreich und der Große Krieg 1914-1918. Die andere Seite der Geschichte. Hg. von Klaus Amann und Hubert Lengauer. Wien 1989, S. 152-158; Claudia Warum: Richard von Schaukal als Übersetzer französischer Literatur. In: Die österreichische Literatur. Ihr Profil von der Jahrhundertwende bis zur Gegenwart (1880-1980). Bd. 1. Hg. von Herbert Zeman. Graz 1989, S. 297-316; Claudia Warum: Une relation littéraire franco-autrichienne. Georges Duhamel et le traducteur des „Elégies et des Ballades“, Richard von Schaukal. In: Georges Duhamel et l'Europe. Actes du colloque (3. fevrier 1990). Hg. von der Association des Amis de Georges Duhamel et de l'Abbeye de Créteil. Paris 1990, S. 69-80.

100 Vgl. Pietzcker: Richard von Schaukal, S. 192-206. 
setzte sich vor allem Claudia Girardi (geb. Warum) mit Schaukals Verbindungen nach Frankreich und mit den brieflichen Kontakten zu mährischen sowie deutschen Dichterinnen und Dichtern auseinander. ${ }^{101}$

Für die theoretische Abgrenzung der Untersuchung kamen entscheidende Impulse von Ester Jiresch, ${ }^{102}$ Edward Timms ${ }^{103}$ und Helga Mitterbauer. ${ }^{104}$ Jiresch und Mitterbauer greifen in ihren literaturwissenschaftlichen Monographien unter anderem auf die Netzwerkforschung bzw. -analyse zurück. Sie verdeutlichen den gesteigerten Stellenwert von Cliquen, Gruppen und Kreisen zu Beginn des 20. Jahrhunderts für eine über den skandinavischen (Jiresch) oder deutschen Sprachraum (Mitterbauer) hinausreichende literarische sowie biographische Signifikanz. Ausschlaggebend für die Erzeugung kultureller Synergien sind zentral positionierte Vermittler, so Timms. Karl Kraus, Franz Blei (1871-1942), aber auch Richard Schaukal, die überdies miteinander in Kontakt standen, waren solche Kultur- und Literaturvermittler. Sie nutzten ihre Netzwerke, um sich einen Informationsvorsprung vor allem in ästhetischen und literaturbetrieblichen Belangen zu verschaffen. Schaukal verfügte über eine lange Kontaktliste, die seinen Stellenwert als Vermittlerinstanz und seine Beteiligung an unterschiedlichen Diskursen der Zeit verdeutlicht, in der Wiener-Moderne-Forschung jedoch unbeachtet blieb. Neben Claudia Girardi erinnert lediglich Florian Krobb an Schaukals Rolle als Vermittler französischer Avantgardeliteratur. Krobb stellt ihn in dieser Funktion sogar Hermann Bahr (1863-1934) und Marie Herzfeld (1855-1940) zur Seite. ${ }^{105}$

Es drängt sich die Frage auf, warum nun aber Schaukal, der die europäischen Literaturbewegungen „seismographisch“106 perzipierte und sich vor allem ab 1900 ins kulturelle Leben Wiens einschrieb, eine Randerscheinung geblieben ist. Eine Entwicklung, die ebenso Franz Blei, Marie Herzfeld und lange Zeit auch Hermann Bahr betroffen hat.

101 Vgl. Claudia Warum: Briefe eines Mährers aus Wien in die Heimat und nach Böhmen. Richard von Schaukal und seine Beziehungen zu den böhmischen Ländern. In: Literatur in Bayern, H. 39 (1995), S. 74-80.

102 Vgl. Ester Jiresch: Im Netzwerk der Kulturvermittlung. Sechs Autorinnen und ihre Bedeutung für die Verbreitung skandinavischer Literatur und Kultur in West- und Mitteleuropa um 1900. Groningen 2013.

103 Vgl. Edward Timms: Dynamik der Kreise, Resonanz der Räume. Die schöpferischen Impulse der Wiener Moderne. Weitra 2013.

104 Vgl. Helga Mitterbauer: Die Netzwerke des Franz Blei. Kulturvermittlung im frühen 20. Jahrhundert. Tübingen/Basel 2003.

105 Vgl. Florian Krobb: [Rez. zu Mitterbauer: Die Netzwerke des Franz Blei]. In: Austrian Studies, Bd. 12 (2004), S. 287-289. http://www.jstor.org/stable/27944737 (zuletzt aufgerufen am 31. Juli 2019).

106 Urbach: Leibhaftiges Dilemma der Jahrhundertwende. 
Bevorzugter Gegenstand der Schaukal-Forschung ist vor allem das 1907 veröffentlichte Buch Leben und Meinungen des Andreas von Balthesser, das zuletzt 2013 wiederaufgelegt wurde. Schaukals Dandy ist der große Wurf einer Schriftstellerkarriere, das Werk markiert den Zenit seines literarischen Schaffens. Untersuchungen, die Balthesser gewidmet sind, beschäftigen sich unter anderem mit der kulturkonservativen Transformation, die der Dandy bei der Übernahme aus dem britischen und französischen Kulturkreis durch Schaukal erfahren hat. ${ }^{107}$ Historische Zäsuren sowie antisemitische und ständestaatliche Haltungen bilden die zeitgeschichtliche oder soziokulturelle Folie und verknüpfen biographische Aspekte mit ästhetisch-poetologischen Analysen. Dabei kreisen die vergleichenden Untersuchungen meist um den Begriff des

107 Ein Weg, der von Österreich wieder zurückführte, wie die Übersetzungen von Balthesser auf Englisch und Italienisch zeigen; vgl. Richard Schaukal: The Life and Opinions of Herr Andreas von Balthesser, Dandy and Dilettante. Nachwort von Michael Kane und Florian Krobb. Riverside (Calif.) 2002; Vita e opinioni del signor Andreas von Balthesser. Übersetzt von Enrico Arosio. Mailand 1986.

Vgl. die Forschungsbeiträge zum Thema: Stephanie Inzinger: Dandyistische Charaktere der deutschsprachigen Dekadenzliteratur in Werken von Arthur Schnitzler, Richard von Schaukal und Thomas Mann. Diplomarbeit Univ. Wien, 2013; Ester Saletta: Dandytum als ästhetische Geisteshaltung der männlichen Weltanschauung der Wiener Jahrhundertwende am Beispiel von Richard von Schaukals „Leben und Meinungen des Herrn Andreas von Balthesser, eines Dandy und Dilettanten, mitgeteilt von Richard Schaukal“ (1907). In: „Ich bin ein Mann! Wer ist es mehr?“ Männlichkeitskonzepte in der deutschen Literatur vom Mittelalter bis zur Gegenwart. Hg. von Barbara Hindinger und Martin Langner. München 2011, S. 209-233; Libor Marek: Schaukals literarischer Dandy im Spiegel der konservativen Revolution. In: Bohemica Olomucensia, H. 3 (2009), S. 257-261; Jörg Schönert: Glossen, Gespräche und Geschichten zum ,Dandy-Pop‘. „Leben und Meinungen des Herrn Andreas von Balthesser, eines Dandy und Dilettanten, mitgeteilt von Richard Schaukal“ (1907). In: Pop in Prosa. Erzählte Populärkultur in der deutsch- und ungarischsprachigen Moderne. Hg. von Amália Kerekes u. a. Frankfurt am Main u.a. 2007, S. 15-27; Andres Wicke: Der paradoxe Dandy. Richard Schaukals „Leben und Meinungen des Herrn Andreas von Balthesser“. In: Literatur und Leben. Anthropologische Aspekte in der Kultur der Moderne. Festschrift für Helmut Scheuer zum 60. Geburtstag. Hg. von Günter Helmes u. a. Tübingen 2002, S. 147-160; Julia Bertschik: Ein Dandy liest Raabe: Zu einer Episode aus der Geschichte der „Mitteilungen für die Gesellschaft der Freunde Wilhelm Raabes" in der Zwischenkriegszeit. In: Eros Thanatos, Bd. 5-6 (2001/2002), S. 19-26; Florian Krobb: „denn Begriffe begraben das Leben der Erscheinungen“: Über Richard von Schaukals „Andreas von Balthesser“ und die ,Eindeutschung“ des Dandy. In: Eros Thanatos, Bd. 3-4 (1999/2000), S. 89-111; Markus Tinhof: Richard Schaukals „Leben und Meinungen des Andreas von Balthesser“ im Kontext der literarischen Charakterologie. In: Eros Thanatos, Bd. 1 (1997), S. 65-88; Claudia Warum: Richard von Schaukal und der Dandyismus. In: Literatur ohne Grenzen. Festschrift für Erika Kanduth. Hg. von Siegfried Loewe, Alfred Noe und Alberto Martino. Frankfurt am Main u. a. 1993, S. 441-476; Ihrig: Richard von Schaukal. 
„Epigonentums“. ${ }^{108}$ Der Vergleich mit literarischen „Vorgängern und Zeitgenossen“109 erfolgt häufig mit Blick auf Andreas von Balthesser. Balthesser ist nicht allein in Anlehnung an den französischen und britischen Dandytypus entstanden, sondern transportiert ein auf die Doppelmonarchie fokussiertes, eigenständiges Selbstbewusstsein. Das und die innovative Vermischung verschiedener Gattungs- und Autorschaftskonzepte mag zur breiten Rezeption beigetragen haben. ${ }^{110}$ Obwohl sich Schaukal vor allem in späteren Texten gegen eine Gleichsetzung mit dem Titelhelden wehrte und in seinem Anliegen missverstanden zeigte, legte er selbst immer wieder autobiographische Fährten. Die Abhandlung Vom Geschmack (1910) widmete Schaukal „seinem lieben Andreas von Balthesser“. Der Erfolg des Dandybuchs dient jedenfalls bis heute als Legitimation für die Biographie- und Untersuchungswürdigkeit Richard Schaukals. Gleichzeitig macht Andreas von Balthesser das vermeintliche Scheitern seiner poetischen Ansprüche umso deutlicher, da das Werk als literarischer Glanzpunkt und ökonomischer Erfolg einer ansonsten durchschnittlichen Schriftstellerkarriere gewertet wird. Andreas von Balthesser schrieb sich in den weiteren Literaturkanon der Wiener Moderne ein und erzeugte im Umkehrschluss ein Bild, das Richard Schaukal mit der österreichischen Version des Dandys gleichsetzt.

\subsection{Biographie und Kanon}

Jan Assmanns Ausführungen zu Bedeutung und Funktion des kulturellen Gedächtnisses stehen auch mit der Biographietheorie in Kontext, handeln sie doch von kollektiven Tradierungsverfahren (in frühen Hochkulturen) und von der Bedeutung, die Kanons für schriftlich geprägte Gesellschaften einnehmen. In seiner Studie bezeichnet Assmann das kulturelle Gedächtnis als Ort der Objektivierung von alltäglichen Ereignissen und individuellen Erinnerungen, die durch die Wiederholung im Ritus Bestand haben; in einem gemeinschaftlichen Selektionsverfahren werden bedeutungsvolle kollektive Erinnerungen gebündelt, mit symbolischem Wert versehen und im kulturellen Gedächtnis abgespeichert. Die

108 Pietzcker: Richard von Schaukal, S. 13. Auch Peter Sprengel handelt Schaukal und Zweig unter dem Epigonalitätsbegriff ab; vgl. Sprengel: Geschichte der deutschsprachigen Literatur 1900-1918. Von der Jahrhundertwende bis zum Ende des Ersten Weltkriegs. München 2004, S. $249-251$.

109 Pietzcker: Richard von Schaukal, S. 13.

110 Vgl. Peter-André Alt: Mode ohne Methode? Überlegungen zu einer Theorie der literaturwissenschaftlichen Biographik. In: Grundlagen der Biographik, S. 23-39. 
Herstellung von Wirklichkeit durch das kulturelle Gedächtnis bewirke ,Kohärenz'. Assmann geht davon aus, dass der Übergang von ursprünglich rituellen Mnemotechniken, die der Erzeugung und Bewahrung von Kohärenz dienten, auf textuelle Speichertechniken die Herausbildung von Kohärenz destabilisiert habe. ${ }^{111}$ Die Entwicklung von Schrift, die ausgelagerte Speicherung von Schriftlichkeit (bis hin zu Festplatten) und das expansive Entstehen von ganz unterschiedlichen schriftlichen Zeugnissen garantiere keineswegs mehr die Tradierung ihrer Inhalte oder die Implementierung in das kulturelle Gedächtnis. Somit sei ein Blockieren von Sinn im Fluss der Traditionen - wie es der Kanon vollzieht - für die Herstellung von textueller Kohärenz entscheidend. Kurz: Die Entwicklung und Veränderung von Schriftlichkeit evozieren Reaktionen wie die Kanonisierung.

Klassikforschung und Kanontheorie verschmelzen in jüngster Zeit zu einem gemeinsamen Untersuchungsfeld. Sie rücken den auch für die Biographik entscheidenden Prozess der Herstellung von Kanons sowie die daran beteiligten Akteure in den Forschungsfokus. Diese „Agenten“ wirken an der Kanonbildung und Klassikergenese gleichermaßen mit. ${ }^{112}$ Die komplexe, dynamische Erzeugung von Kanons und Klassikern ist mit dem Blick in die Vergangenheit verbunden. Zurückliegende literaturgeschichtliche Zeiträume werden reduktionistisch geordnet, als wertvoll erachtete Inhalte bewahrt und dabei auch personifiziert (Schaukals Zeitgenossen beginnen, von der ,Goethezeit‘ zu sprechen).

Vor allem seit 1968 regte sich aber auf Seiten einer kritischen Literaturwissenschaft Widerstand gegen die identitätsstiftende, repressive Funktion von Kanons und gegen eine auf biographische Größe aufbauende Klassizität. ${ }^{113}$ Theodore Ziolkowski weist in einer begriffsgeschichtlichen Einordnung auf den Umstand hin, dass Kritiker zu Beginn des 20. Jahrhunderts den Begriff ,Tradition“ verwendeten, da ,Kanon' pejorativ konnotiert gewesen sei. ${ }^{114}$ Das trifft

111 Vgl. Jan Assmann: Das kulturelle Gedächtnis. Schrift, Erinnerung und politische Identität in frühen Hochkulturen. München 1999, S. 52-53 und S. 76. Maurice Halbwachs hat davor den Zusammenhang von Erinnerung und ihrer sinnstiftenden Einbettung in ein Milieu beschrieben; vgl. Halbwachs: Les cadres sociaux de la mémoire. Paris 1925. Als Beispiele für weitere Forscherinnen und Forscher, die sich mit dem Thema beschäftigt haben beziehungsweise beschäftigen, sind Aleida Assmann, Reinhart Koselleck, Henry Rousso und Paul Ricœur zu nennen.

112 Robert Charlier und Günther Lottes: Vorwort. In: Kanonbildung. Protagonisten und Prozesse der Herstellung kultureller Identität. Hg. von Robert Charlier und Günther Lottes. Hannover 2009, S. 7-12, hier S. 7.

113 Vgl. Theodore Ziolkowski: Zur Politik der Kanonbildung. Prolegomena zum Begriff einer literarischen ,Klassik‘ in Deutschland (1800-1835). In: Kanonbildung, S. 33-50, hier S. 42-43. 114 Vgl. Ziolkowski: Zur Politik der Kanonbildung, S. 41-42. 
auch auf Schaukals kritische Schriften zu. Allerdings handelt es sich bei Kanon und Tradition um komplementäre Kategorien. Nach wie vor orientiert sich das interessierte Leseklientel an der Selektion von Kritikerautoritäten. Auch wenn aktuelle Kanonlisten zeitgenössische Werke einbeziehen, spielt die Verbindung von Tradition und Kanon eine grundlegende Rolle für die Etablierung des kulturellen Gedächtnisses und für die Erzeugung von Kohärenz. Nach Assmann liegt die Bedeutung von Kanons in der stabilisierenden Festlegung auf Texte, die im Fluss der Tradition schriftlich geprägter Gesellschaften verloren zu gehen drohen und als Gemeinschaftsstabilisatoren dem Vergessen entrissen werden. ${ }^{115}$ Nationale Identifikatoren, auch aus dem Bereich der Literatur, stehen in einem ,grenzenlosen Europa‘ hoch im Kurs.

Kanons erfüllen für die jeweilige Gegenwart, von der aus sie konstituiert werden, und für die Agenten einer bestimmten literarischen Ausrichtung Zwecke, die über die Festlegung auf ästhetische Vorbilder hinausgehen. Diese bestehen laut Robert Charlier, der damit indirekt auch auf Assmann rekurriert, einerseits in der „Selbst- und Fremdvergewisserung von Sprach- und Kulturgemeinschaften“. Andererseits könnten Kanondebatten bestehende Traditionen hinterfragen und somit als Reflexe auf kulturelle Krisen gewertet werden. ${ }^{116}$

In jedem Fall geht die Konstituierung von Kanons mit Machtausübung konform, wie sich nicht nur auf dem literarischen Markt, sondern auch in sprachpolitischer Hinsicht zeigt, wenn etwa Dialekte dem Standard weichen und Minderheitensprachen kulturell homogenisiert und zum Verschwinden gebracht werden. ${ }^{117}$ Im 18. Jahrhundert waren die Kontroversen darüber, welche Variante des Deutschen sich als Schriftsprache durchsetzen solle, eng mit der Frage nach der ,mustergültigen' Sprachverwendung und dem moralischen Gehalt in literarischen Texten verbunden. Im Italien des 16. Jahrhunderts beeinflusste der Rückgriff auf die Sprache in den Werken der tre corone (Dante, 1265-1321, Boccaccio, 1313-1375 und Petrarca, 1304-1374) die questione della lingua, also die Frage nach der Festlegung einer Variante des Italienischen als Schriftsprache, zugunsten des Toskanischen. Der Rückbezug auf die drei Dichter des 13.

115 Vgl. Ralf Zschachlitz: „Kanonische Stillstellung“, „Symbolisches Kapital“, „Dialektik im Stillstand“ - zur Kanontheorie bei Jan Assmann, Pierre Bourdieu und Walter Benjamin. In: Kanon heute. Literaturwissenschaftliche und fachdidaktische Perspektiven. Hg. von Christof Hamann und Michael Hofmann. Baltmannsweiler 2009, S. 13-28, hier S. 15-16.

116 Robert Charlier: Klassikermacher. Goethes. Berliner ,Agenten“ der literarischen Kanonbildung. In: Kanonbildung, S. 51-69, hier S. 51-52.

117 Vgl. Michael Hofmann: Für einen offenen Kanon. Überlegungen im Anschluss an die aktuelle Kanon-Diskussion. In: Kanon heute, S. 29-42, hier S. 31. 
und 14. Jahrhunderts war für Pietro Bembo (1470-1547) der Ausgangspunkt seiner Kodifizierung des Italienischen. ${ }^{118}$

Tendenzen einer nationalstaatlich orientierten Kanonformierung finden sich insbesondere im 19. und zu Beginn des 20. Jahrhunderts, als eine Nationalliteratur etabliert werden sollte und das literarische wie auch wissenschaftliche Feld (darunter Biographie und Historiographie) zum Schauplatz nationaler Kulturkämpfe avancierte. Die Vorstellung von einer übernationalen Weltliteratur, die mit Goethe (1749-1832) eigentlich auf das frühe 19. Jahrhundert zurückgeht, verschwindet ab der zweiten Hälfte desselben Jahrhunderts infolge zunehmender Nationalisierungsbestrebungen. ${ }^{119}$

Dichter wie Hugo von Hofmannsthal und Schaukal galten vor Ausbruch des Weltkriegs als literarische Kosmopoliten, reihten sich dann aber in die Riege der Künstler ein, die ein deutschnationales Gemeinschaftsgefühl poetisch und in Form der Kanonfestlegung umzusetzen versuchten. ${ }^{120}$ Hofmannsthals Beitrag im Rahmen der Erzeugung eines politisch durchdrungenen Nationalkanons greift Karl Kraus in Die letzten Tage der Menschheit satirisch auf. Darin liest ein ,Zyniker - begleitet von spitzen Bemerkungen - einen in der Zeitung abgedruckten offenen Brief Hermann Bahrs an den „in Waffen“ stehenden Hofmannsthal vor: ${ }^{121}$

118 Vgl. Sandra Ellena: Die Rolle der norditalienischen Varietäten in der „Questione della lingua“. Eine diachrone Untersuchung zu Sprachbewusstsein, Sprachwissen und Sprachbewertung. Berlin/Boston 2011, S. 40-103. In seinem Essay „De la littérature allemande“ ging bereits Friedrich II. von linguistischen Standpunkten für die Herstellung eines deutschsprachigen Kanons aus, wie Katharina Mommsen ausführt; vgl. Mommsen: Potsdam und Weimar um 1780. Gedanken zur Kanonbildung anlässlich von Friedrichs II. „De la littérature allemande“. In: Kanonbildung, S. 13-32, vor allem 19-20.

119 Vgl. Peter Goßens: Weltliteratur. Modelle transnationaler Literaturwahrnehmung im 19. Jahrhundert. Stuttgart/Weimar 2011, S. 14-32. Als Gegenkonzept wäre Hermann Hesses Bibliothek der Weltliteratur (Leipzig 1929) zu nennen, die nicht nur relevante Werke des abendländisch und christlich geprägten europäischen Kulturkreises vorstellt, sondern auch den asiatischen, arabischen und persischen Literaturraum miteinbezieht und einen zeitlichen Bogen von 2000 Jahren spannt. Alexander Roda Roda publizierte bereits 1910/1911 eine Anthologie zum Welthumor. Der zweite Band enthält Auszüge aus Schaukals Balthesser und trägt in Anbetracht der wenige Jahre später folgenden kriegerischen Ereignisse den makaber wirkenden Untertitel „Ein fröhliches Jahrhundert“.

120 Vgl. Heinz Lunzer: Hofmannsthals politische Tätigkeit in den Jahren 1914-1917. Frankfurt am Main/Bern 1981.

121 Ende August 1914 sandte Bahr im Neuen Wiener Journal (26. August 1914, S. 6) einen öffentlichen „Gruß an Hofmannsthal“, der später auch im Berliner Tageblatt abgedruckt wurde; vgl. Rolf-Bernhard Essig: Der offene Brief. Geschichte und Funktion einer publizistischen Form von Isokrates bis Günter Grass. Würzburg 2000, S. 208. 
„Und das wollen wir uns jetzt merken für alle Zeit: es gilt, dabei zu sein. Und wollen dafür sorgen, daß wir hinfort immer etwas haben sollen, wobei man sein kann. Dann wären wir am Ziel des deutschen Wegs, und Minnesang und Meistersang, Herr Walter von der Vogelweide und Hans Sachs, Eckhart und Tauler, Mystik und Barock, Klopstock und Herder, Goethe und Schiller, Kant und Fichte, Beethoven und Wagner wären dann erfüllt. -“ Wie hängen denn die mit dir zusammen? Ah, er meint vielleicht, daß sie enthoben sind. „Und das hat unserem armen Geschlecht der große Gott beschert! Gott sei Dank!“‘122

\subsection{Biographie als Erinnerungsort}

Auch Orte, Ereignisse und Personen können im kollektiven Gedächtnis fixiert werden, sind in Form von Dichterhäusern topographisch lokalisierbar oder als Erinnerungsort lesbar. Der Kanon ist in diesen Fällen die steingewordene Leistungsschau großer Persönlichkeiten, Schauplätze, Taten und Werke einer Nation, die in Abgrenzung oder im Vergleich zum Kanon der anderen Nationen das Selbstbild bekräftigt und eine kulturelle, vor allem aber auch nationale Identität mit herausbildet.

Die dreibändige Ausgabe Deutsche Erinnerungsorte, die in Anlehnung an Pierre Noras in den 1980er und frühen 1990er Jahren verfassten Les lieux de mémoire entstanden ist, ${ }^{123}$ belegt einen neueren (historiographischen) Beitrag zur Erzeugung von Klassizität und Kanonbildung. Zwar problematisieren die Herausgeber in der Einleitung eine Festlegung auf deutsche Erinnerungsorte und die strikte Orientierung am französischen Modell, da deutsche Geschichte durch eine späte Nationalstaatswerdung sehr viel heterogenere Erinnerungsorte erzeuge und aufgrund der historischen Ereignisse im 20. Jahrhundert wesentlich mehr Brüche, Krisen, Tragödien und Traumata zu bewältigen habe. Dennoch richte sich der Fokus auf „Erinnerungsorte von nationaler Bedeutung“, denn in „unseren Erinnerungen erkennen wir, wer wir sind, was wir werden wollen und worin wir uns von anderen unterscheiden." ${ }^{124}$ Das widerspricht der später formulierten europäischen Intention des Projekts, das nicht sinnstiftend wirken möchte und ,Deutschland“ vom historischen Standpunkt des jeweiligen Epochenkontextes aus betrachtet, den die Essays behandeln. ${ }^{125}$ Neben dieser Argumentation, die

122 Karl Kraus: Die letzten Tage der Menschheit. Tragödie in fünf Akten mit Vorspiel und Epilog. Frankfurt am Main 1986, S. 147 (1. Akt, 19. Szene).

123 Vgl. Pierre Nora (Hg.): Les lieux de mémoire. 3 Bde. Paris 1997; Étienne François und Hagen Schulze (Hg.): Deutsche Erinnerungsorte. 3 Bde. München 2001.

124 François und Schulze: Deutsche Erinnerungsorte, S. 18 und S. 13.

125 Vgl. François und Schulze: Deutsche Erinnerungsorte, S. 19. 
sich insgesamt auf eine Art postmoderne Vielbezüglichkeit in einem offenen Reflexionsrahmen über (Kultur-)Geschichte stützt, weisen die deutschen Erinnerungsorte eine eklatante Unterrepräsentanz hinsichtlich bedeutender Vertreterinnen für ein „deutsches kulturelles Gedächtnis“ auf. Abgesehen von Uta von Naumburg, Rosa Luxemburg (1871-1919), Königin Luise (1776-1810) und Marlene Dietrich (1901-1992) greifen die personenbezogenen Essays der drei Bände auf altbekannte ,deutsche Männer` zurück. Personen bilden, gemäß der metaphorischen Bedeutung, die die Herausgeber den Erinnerungsorten zusprechen, ebenso einen kollektiven Gedächtnisraum wie physische Orte, Emotionen und politische Begrifflichkeiten. ${ }^{126}$ Goethe, Schiller (1759-1805), Nietzsche (1844-1900), Einstein (1879-1955), Bismarck (1815-1898), sie alle hatten zweifelsohne prägenden Einfluss von historischem Ausmaß, untermauern aber auch eine nach wie vor existierende Hinwendung zum biographiewürdigen Leben ,männlicher Heldenfiguren' und eine auf diesen Typus gründende nationale Identität. Laut Alois Hahn bilden Nation und Territorium die erfolgreichsten Modelle für Identitätsbildung in Europa. ${ }^{127}$ Assmann beschreibt die textuelle Erzeugung symbolisch relevanter Erinnerungen für das kulturelle Gedächtnis. Die ,Erinnerungsorte belegen dementsprechend, wie auch gegenwärtig noch männliche Persönlichkeiten symbolisch aufgeladen, für eine ,nachhaltige“ Auseinandersetzung empfohlen und in ein kulturelles Gedächtnis eingeschrieben werden. Hier vermag die Biographietheorie methodisch zu intervenieren und einer veralteten Form der Heldenverehrung in neuen Gewändern zu begegnen.

Auch der von Robert Charlier und Günther Lottes herausgegebene aufschlussreiche Sammelband Kanonbildung aus dem Jahr 2009, auf den einige der hier ausgeführten Überlegungen zurückgehen, reflektiert zwar den Konstruktionscharakter von Kanons, also den Herstellungsprozess, der Autoren, ausgewählte Werke und Agenten selektiver Erzeugung (Kritiker, Verleger etc.) erstmals in einen gemeinsamen theoretischen Rahmen einbindet. Doch liegt der Fokus hier mehrheitlich auf Goethe und der Weimarer Klassik. Selbst der Beitrag zum Kanonausschluss wird am ,Dichterfürsten' festgemacht. Der Sammelband leistet somit der Festigung eines Goethe-Kanons Vorschub und trägt zur Stabilisierung der Kohärenz bei, Deutschland sei eine Weimarer Kulturnation.

Ebenso auf 2009 datiert der bereits zitierte Sammelband Kanon heute von Christof Hamann und Michael Hofmann, der an die erste grundlegende Aufarbeitung des Themas im deutschen Sprachraum anknüpft. Der 1998 von Renate

126 François und Schulze: Deutsche Erinnerungsorte, S. 17-18.

127 Vgl. Alois Hahn: Konstruktionen des Selbst, der Welt und der Geschichte. Frankfurt am Main 2000, S. 17. 
von Heydenreich herausgegebene Band Kanon Macht Kultur bündelt die Ergebnisse eines großangelegten Projekts zum Thema. Die Beiträger fordern darin eine differenzierte Herangehensweise an den Kanon- und Klassikerbegriff und reflektieren kritisch Prozesse der Kanonisierung und ihre Politisierung. ${ }^{128}$

Für Michael Hofmann, einen der Herausgeber von Kanon heute, vermittelt der Kanon „die angebliche Existenz einer homogenen Kultur, die vor allem seit dem frühen 19. Jahrhundert bildungsbürgerlich geprägt ist. “129 Er spricht sich in Anlehnung an Kanon Macht Kultur für einen offenen, enthierarchisierten Kanon aus, der Traditionen und Sprachgrenzen eines Landes überwindet und den gesellschaftlichen Pluralismus berücksichtigt. ${ }^{130}$

Mit Blick auf den literarischen Kanon liegt heute sein auch lukrativer Zweck in der Kompilierung von Werken, die hinsichtlich der ästhetischen Wertschätzung und Bedeutsamkeit dem breiten Konsens entsprechen. Kanons werden von Lehrenden an Universitäten als Literatur- und Leselisten erzeugt, von Einzelpersonen wie Marcel Reich-Ranicki hergestellt, ${ }^{131}$ als Bestseller gelistet oder von Zeitungen als Reihen herausgegeben. Im Fall der Süddeutsche Zeitung Bibliothek, die Hundert große Romane des 20. Jahrhunderts erfolgreich neu edierte (und die kriselnde Tageszeitung sanierte), ${ }^{132}$ wird die Beliebtheit solcher Anthologien bei einer breiten Leserschicht ersichtlich. Die Edition bündelte ein überschaubares Angebot literarischer Werke, von deren Wichtigkeit das Lesepublikum mit Bildungsanspruch aufgrund der SZ-Etikettierung überzeugt war. Während sich Reich-Ranickis Kanon auf den deutschsprachigen Raum konzentrierte und alle Gattungen vom Mittelalter bis zur Gegenwart abzudecken suchte, beschränkte sich die SZ-Edition auf Romane des 20. Jahrhunderts, bezog aber auch Werke der Weltliteratur mit ein. Ein im Nachrichtenmagazin Der Spiegel von Volker Weidermann kompilierter Kanon

128 Vgl. Renate von Heydebrand (Hg.): Kanon Macht Kultur. Theoretische, historische und soziale Aspekte ästhetischer Kanonbildung. Stuttgart/Weimar 1998.

129 Hofmann: Kanon heute, S. 31.

130 Siehe vor allem den Anhang des Beitrags, der einen solchen offenen Kanon als Diskussionsgrundlage vorschlägt; Hofmann: Kanon heute, S. 39-42.

131 Vgl. die 2006 abgeschlossene, 50 Bände umfassende Anthologie Der Kanon. Die deutsche Literatur.

132 Dirk Rumberg spricht von 11,3 Millionen verkauften Bänden zwischen März 2004 und Juni 2005, somit sei die Reihe eines der erfolgreichsten Editionsprojekte der letzten Jahre, vgl. Rumberg: Eine Erfolgsgeschichte. In: Hundert große Romane des 20. Jahrhunderts. Hg. von Thomas Steinfeld. München 2008, S. 238-239, hier S. 238. Auch Die Zeit veröffentlichte einen Kanon von einhundert Romanen, die Fritz. J. Raddatz 1980 bei Suhrkamp herausgegeben hat. 
,wichtiger“ internationaler Romane setzt beim „Epochenbruch 1989“ an und verbindet politische mit literarischer Bedeutsamkeit. ${ }^{133}$

Kanonisierung geht also stets mit der Herstellung oder, wie rezente Beispiele zeigen, mit der Infragestellung von (literarischer) Autorität sowie mit Selektion einher, worin auch immer die Gründe für eine solche Auswahl liegen. Die Engführung eines eigentlich sehr breiten literarischen Panoramas regte Literaturwissenschaftler zu quantitativen Untersuchungen an, die auf computergestützte Verfahren zurückgreifen und Literaturgeschichte aus der Vogelperspektive betrachten. Franco Moretti beschreibt in La letteratura vista da lontano, wie ihn die Untersuchung von Nationalbibliographien darauf aufmerksam machte, dass er sich durch den Fokus auf das Besondere und NichtWiederholte den Zugang zu einem weiteren Erkenntnisrahmen verbaut habe. Dem setzt er die Methode des distant reading entgegen, die die literaturgeschichtliche Kanonbildung unterminiere, indem alle veröffentlichten Romane in einen übergeordneten Kontext gestellt würden (etwa entsprechend der Fragestellung, in welchem Zeitraum die meisten Romane publiziert wurden). Literarische Sensationen bekämen denselben Wert zugesprochen wie die sehr viel größere Zahl an vergessenen Büchern und literarischen Flops. Anhand von Graphen, Karten und Stammbäumen - drei Visualisierungsmöglichkeiten aus anderen wissenschaftlichen Disziplinen - wird nicht der Einzelfall, sondern die Wiederholung beziehungsweise diachrone Entwicklung literaturgeschichtlicher Phänomene dargestellt. ${ }^{134}$

\section{Netzwerkforschung: Metapher und Methode}

Die Analyse von Netzwerken, Beziehungsgeflechten, sozialen Ordnungsmustern und Verbindungen ist eine Methode, die in erster Linie auf die Sozial- und Geschichtswissenschaften zurückgeht. Globalisierung, Technisierung, die fortschreitende Digitalisierung, aber auch die Kritik an der klassischen Soziologie lenkten den Blick verwandter Disziplinen zunehmend auf die Netzwerkforschung als heterogene „Methode mittlerer Reichweite.“135

133 Volker Weidermann: Die Bücher unserer Zeit. In: Der Spiegel, H. 42/2016 (15. Oktober 2016), S. 117-127.

134 Vgl. Franco Moretti: La letteratura vista da lontano. Turin 2009, S. 7 und S. 10-11.

135 Christian Stegbauer und Roger Häußling (Hg.): Handbuch Netzwerkforschung. Wiesbaden 2010, S. 57. 
Das Handbuch Netzwerkforschung erläutert die methodische Bandbreite anhand von fünf Anwendungsfeldern. ${ }^{136}$ Die meisten netzwerkanalytisch ausgerichteten Arbeiten betonen ihre interdisziplinäre Ausrichtung und den daraus resultierenden methodischen, aber auch visuellen Wert. ${ }^{137}$ „Mit der zunehmenden Verwendung von netzwerkanalytischen Theorieansätzen und Forschungsmethoden“, so Dorothea Jansen, sei „heute die Bereitschaft gewachsen, netzwerkanalytische Ansätze mit anderen Theorieansätzen zu verbinden. Netzwerkanalytisch arbeitende Wissenschaftler [...] bauen komplexere Erklärungsmodelle, in denen [. . .] insbesondere auch kulturelle [. . .] Erklärungsgrößen verwendet werden.“`138

Gerade netzwerkanalytische Projekte vollziehen die „Interaktion zwischen Netzwerkanalyse und traditionellen Forschungsmethoden"139 aus den Natur-, Kultur- und Sozialwissenschaften. ${ }^{140}$ Die Akteur-Netzwerk-Theorie stellt ein Beispiel für die Fusion unterschiedlicher Wissenschaftsfelder und ihrer soziologischen Nachbardisziplinen dar.

Auch in der Biographieforschung ist ein gesteigertes Interesse an innovativen Ansätzen bemerkbar, die von der linearen Schilderung eines Lebens abweichen, kollektive Betrachtungsweisen einbeziehen und neben der Zeitebene auch für die Biographie wichtige Topographien berücksichtigen. Biographietheorie und Netzwerkforschung interagieren wiederum mit den Digital Humanities, um neue Methoden in der Darstellung, Sammlung und Verknüpfung von biographischen Daten zu erproben.

Das Netz steht aber auch metaphorisch für die technologischen, infrastrukturellen und ökonomischen Entwicklungen seit dem 19. Jahrhundert und den daraus resultierenden neuen Wahrnehmungsformen. ,Spinnennetz' und ,Netzwerk` zählen zu gängigen Wissenschaftsmetaphern. In ihrer Unterscheidung liegt bereits ein Wesensmerkmal und Grundproblem der Netzwerkforschung: Während soziale Medien oder elektrotechnische und neuronale Netzwerke die Auffassung von relational-kollaborativen Austauschprozessen mehrerer Elemente oder Akteure suggerieren, die polyzentrisch positioniert sind, richtet sich der Blick beim Spinnennetz auf einen zentral positionierten Akteur, der

136 Vgl. das Inhaltsverzeichnis von Stegbauer und Häußling (Hg.): Handbuch Netzwerkforschung, S. 8-10.

137 Vgl. Thomas Schweizer: Muster sozialer Ordnung. Berlin 1996, S. 9 und S. 112.

138 Dorothea Jansen: Einführung in die Netzwerkanalyse. Opladen 2003.

139 Marten Düring u. a.: Einleitung. In: Handbuch Historische Netzwerkforschung. Grundlagen und Anwendung. Hg. von Marten Düring u. a. Berlin 2016, S. 5-10, hier S. 7; vgl. auch Christian Nitschke: Die Geschichte der Netzwerkanalyse In: Handbuch Historische Netzwerkforschung, S. 11-29, hier S. 11.

140 Siehe zum Beispiel die Ausführungen von Friedrich Lenger: Netzwerkanalyse und Biographieforschung - einige Überlegungen. In: Bios, 18. Jg., H. 2 (2005), S. 180-185. 
sich die Interessen und Fähigkeiten der anderen Akteure zunutze macht, um nicht zu sagen, sie sich einverleibt.

Die vorliegende Untersuchung setzt keine quantitative, computergestützte und graphische Netzwerkvisualisierung um. Der Erkenntnisgewinn der Visualisierung würde durch die Zentrierung auf Schaukal zu gering sein. Im Zentrum stehen Fragestellungen und die terminologische Verschaltung von Netzwerkforschung, Biographietheorie und Literaturwissenschaft, um den Fokus auf zum Teil unerwartete literarische Beziehungen und biographische Positionierungen von Akteuren im sozialen Raum zu lenken. Netzwerkanalysen richten den Blick auch auf das Nicht-Vernetzte ${ }^{141}$ und auf Akteure, die aus den Konstellationen sozialer Ordnung ausgeschlossen sind. Die Gefahr, Hierarchien und Machtkonstellationen aufgrund der flachen Struktur von Netzwerken zu übersehen, soll mit Bezug auf Bourdieus Feldbegriff eingedämmt werden.

Eine Verbindung zwischen Netzwerkforschung und Feldtheorie besteht zunächst im „methodologischen Relationismus“; Feld und Habitus seien „Bündelungen von Relationen“, so Loïc Wacquant. Eine nicht-relationale Kategorie sei hingegen das Kapital, womit individualspezifisch die Einsatzmittel bezeichnet werden, die jedem Akteur zur Verfügung stehen, um sich im Feld zu positionieren. Diese Einsatzmittel, aus denen einflussreiche und komfortable gesellschaftliche Positionen resultieren können, sind in quantitativ ausgerichteten Netzwerkanalysen nicht leicht darzustellen. Bourdieus Kritik an der Netzwerkforschung betrifft ihre empirische Ausrichtung auf die Interaktionsbeziehungen, die etwa die Kapitalstruktur ausblende. ${ }^{142}$ Auf der anderen Seite lässt sich auch Bourdieus Auffassung von Kapital und seiner Wirkmacht in der sozialen Welt kritisieren. Für ihn bedeuten alle Austauschprozesse Positionierungskämpfe, ganz gleich, ob es sich um persönliche Gespräche oder karitative Ziele handelt.

Netzwerktheorie und Biographik zeichnen sich durch methodische Kompatibilität aus. Ihr Reiz scheint gerade im Zusammenspiel von diskursiver, methodischer und technologischer Anschaulichkeit zu liegen. Pierre Bourdieu vergleicht in seinen soziologischen Erklärungen die soziale Welt mit physikalischen Kraftfeldern. Die Akteure bewegen sich darin dynamischen Elektronen gleich. Auch David Nye spielt in seiner Anti-Biographie über Thomas Edison auf Phänomene der Natur an: „Wie bei einem Elektron in einem Orbital konnte ich seine Energie

141 Vgl. Osterhammel: Die Verwandlung der Welt, S. 1010.

142 Vgl. Loïc Wacquant: Auf dem Weg zu einer Sozialpraxeologie. Struktur und Logik der Soziologie Pierre Bourdieus. In: Pierre Bourdieu und Loïc Wacquant: Reflexive Anthropologie. Aus dem Franz. von Hella Beister. Frankfurt am Main 1996, S. 17-93, hier S. 34-40. Diese Auffassung greift Roger Häußling kritisch auf: Relationale Soziologie. In: Handbuch Netzwerkforschung, S. 63-87, hier S. 68. 
und Bewegung beschreiben, aber ich konnte nicht mit Exaktheit sagen, wo er sich, psychologisch gesprochen, zu irgendeinem bestimmten Zeitpunkt befunden hatte. “143 Dabei wird die metaphorische Verbindung zwischen physikalischen Erscheinungsformen und der biographischen Zugangsweise bei Edison, einem maßgeblichen Erfinder im Bereich der Elektrotechnik, ersichtlich. In seiner kulturwissenschaftlichen Arbeit beschreibt auch Edward Timms die Wiener Kreise um 1900 als „elektromagnetische Netzwerke“, in denen Schlüsselfiguren der Jahrhundertwende gleich mehreren Kreisen angehörten und für eine rasche Verbreitung neuer Ideen sorgten. ${ }^{144}$ Und Osterhammel konstatiert: „Die Zeit zwischen der Jahrhundertmitte und dem Ersten Weltkrieg [...] war eine Periode beispielloser Netzwerkbildung. “ 145

Aus biographietheoretischer Sicht besteht ein Kritikpunkt an Netzwerkanalysen, die auf nur einen Akteur ausgerichtet sind, in der Konstruktion von Biographiewürdigkeit über die Vernetzung mit prominenteren Dichtern. Je weniger präsent und bekannt eine untersuchte Figur, desto größer scheint der Rechtfertigungsdruck, ihren biographischen Wert zu legitimieren. Die zu untersuchende Person wird dann an relevantere und kanonisierte Protagonisten gekoppelt, um ihre Bedeutung zu unterstreichen. ${ }^{146}$

Eine quantitativ ausgerichtete Netzwerkanalyse, die Schaukal mit denselben Erhebungsmethoden erfasst wie beispielsweise Arthur Schnitzler, Thomas Mann oder Stefan Zweig, würde das Problem der konstruierten Größe zwar umgehen, allerdings blieben bestimmte qualitative Faktoren im Verborgenen. Aus diesem Grund wird die Netzwerkforschung auf andere Theorien abgestimmt. Die Beziehung der Akteure untereinander, ihre Austauschprozesse und Positionen im Netz werden anhand überschaubarer Gruppen qualitativ betrachtet und spezifische Aspekte wie Herkunft, generationaler Zusammenhang und Karriere in den Vergleich miteinbezogen. Der Blick auf die Vernetzung opponiert dabei dem Individualitätsbegriff, also der Vorstellung vom „invariablen ,Kern“ [...] einer gegebenen Substanz personaler Identität.“147

Die Verbindung von Netzwerkforschung und Biographik ist eine Absage an die Geschlossenheit und Linearität der dargestellten Leben; die vorliegende Untersuchung berücksichtigt deshalb auch nur sekundär die chronologische Abfolge von Ereignissen und konzentriert sich vielmehr auf Momente des sozialen

143 Nye: Nach Thomas Edison, S. 353.

144 Timms: Dynamik der Kreise, S. 16.

145 Osterhammel: Die Verwandlung der Welt, S. 1011.

146 Vgl. Zimmermann: Exemplarische Lebensläufe, S. 8.

147 Fetz: Die vielen Leben der Biographie, S. 34. 
Kontaktes sowie auf künstlerische und literaturbetriebliche Diskurse. Die Korrespondenzen sind von Interesse, da sich in ihnen Informalität und Formalität (Privatsphäre und öffentliches Agieren) überschneiden. Selbstverständlich ist die Analyse narrativen Mustern unterworfen und besteht gerade nicht aus unkommentierten Netzwerkgraphiken. So lohnenswert solche quantitativen Ansätze für die Biographietheorie auch wären, eine nachvollziehbare Zusammenführung beziehungsweise ein schlüssiges Narrativ ist für die Verständlichkeit wichtig.

Ein weiterer Kritikpunkt an der Netzwerkforschung ist die Aussparung kognitiv-emotionaler Bedingungen, die das Handeln der Akteure mitbestimmen und den strukturellen Rahmenbedingungen zur Seite gestellt werden müssten. ${ }^{148}$ Das ist für Schaukals Umgang mit den Akteuren aus seinen Netzwerken ein entscheidender Punkt. Seine literarischen Verbindungen waren vielversprechend, doch ergab sich aus der Struktur nicht zwangsläufig eine günstige Kapitallage. An der Beschaffenheit der Netzwerke lässt sich ein Erfolg in den Feldern der sozialen Welt nicht ablesen. Schaukals Kognitionen haben vermutlich dazu beigetragen, dass er bestimmte Karriereziele verfehlte. Nicht oder unzureichend funktionierende Netzwerkverbindungen könnten auf kommunikatives Fehlverhalten und auf einen zu starken Fokus auf Eigeninteressen zurückzuführen sein.

Eine weitere Schwierigkeit liegt in der diachronen Abbildung von Netzwerken und ihren Akteuren. Die Personen, mit denen Schaukal über die Jahre in Kontakt stand, und die Struktur ihrer Verbindungen variierten sehr stark. Diese Prozesse in geeigneter Form nachzuzeichnen, gehört zu den größten Herausforderungen der Netzwerkanalyse, da Netzwerke Momentaufnahmen darstellen. Weil Netzwerkuntersuchungen nur einen begrenzten Zeitraum in den Blick nehmen (können), zeigen sie auch nur einen synchronen Ausschnitt. Die diachrone Komplexität wäre kaum darstellbar. Das umfassende Netzwerkprojekt zum Künstlerkreis Hagenbund positioniert zum Beispiel in einer Netzwerkgraphik die zentralen Akteure, die Schauplätze der Ausstellungen und die Verbindungen untereinander. Zeitlich dynamische Abfolgen oder ästhetische Entwicklungen werden auch darin nicht visualisiert. Sie weichen der Gesamtdarstellung der Netzwerke auf einen Blick. ${ }^{149}$

Nicht zuletzt stellt sich die Frage, ob überhaupt von Schaukal-Netzwerken die Rede sein kann. Handelt es sich bei den Verbindungen nicht lediglich um „sogenannte kognitive, subjektiv wahrgenommene oder ,eingebildete‘ Netz-

148 Vgl. Schweizer: Muster sozialer Ordnung, S. 126.

149 Vgl. die Netzwerkgraphik des Projekts „Hagenbund. Ein europäisches Netzwerk der Moderne (1900 bis 1938)“: http://tools.fas.at/hagenbund/exhibition.html (zuletzt aufgerufen am 31. Juli 2019). 
werke“, ${ }^{150}$ die forschungspragmatisch festgelegt werden? Netzwerkanalysen erklären die Formierung von bestimmten Strukturen nicht ausreichend, so ein Kritikpunkt. ${ }^{151}$ Die Netzwerkkonstituierung, also die Gesamtheit der zu beschreibenden Akteure, entspringt tatsächlich weitestgehend dem Forschungsinteresse und der Materiallage. Sie wird vom Verfasser bestimmt und hat sich nicht aus empirischen Befragungen herauskristallisiert, ist aber für eine qualitative Analyse nichtsdestotrotz aufschlussreich.

Für die relationale Untersuchung Richard Schaukals stellt der Netzwerkansatz einen geeigneten Methodenbaustein dar, da er Kanonisierungsprozesse unterläuft, die ihn in den Wahrnehmungskreis der literarischen Moderne einbinden (oder daraus ausschließen). Die Netzwerkforschung richtet den Blick nicht auf den isolierten Akteur, sondern fokussiert die Verflechtung von Akteuren in einem sozialen System, ihre Interaktion, wie sie eine gemeinsame Struktur und Kognition etablieren ${ }^{152}$ und wie daraus Handlungsmöglichkeiten - oder Beschränkungen - resultieren.

\subsection{Die Beschaffenheit von Netzwerken}

Netzwerke bestehen erstens aus einer begrenzten Menge an Elementen oder Personen (Akteuren), die als ,Knoten“ bezeichnet werden. Zweitens weisen sie eine wiederum begrenzte Zahl an Verbindungen auf, die zwischen den Knoten verlaufen, das sind die sogenannten Kanten. Diese Relationen lassen sich hinsichtlich ihres Inhalts, ihrer Intensität und ihrer Form unterscheiden. ${ }^{153}$ Anhand von ,relationalen Daten“ erfolgt die Netzwerkabgrenzung, also die Festlegung einer bestimmten Menge an Akteuren als Netzwerk. ${ }^{154}$ Für die ,Abgrenzung،, so der Begriff, muss mindestens eine verbindende soziale Beziehung erfasst werden. Dazu zählen Organisations- oder Gruppengrenzen, geographische Grenzen und direkte Interaktionen, etwa Treffen oder gemeinsame Besuche von Veranstaltungen, aber auch affektive Beziehungen und verwandtschaftliche Verhältnisse. ${ }^{155}$

Für die vorliegende Untersuchung liegt der überwiegende Fokus auf Exponenten des literarischen Feldes, mit denen Schaukal postalisch in Verbindung stand. Die gemeinsamen relationalen Daten für die Netzwerkabgrenzung ergeben

150 Jansen: Einführung in die Netzwerkanalyse, S. 86-87.

151 Vgl. Schweizer: Muster sozialer Ordnung, S. 135.

152 Vgl. Schweizer: Muster sozialer Ordnung, S. 113.

153 Vgl. Jansen: Einführung in die Netzwerkanalyse, S. 58-59.

154 Vgl. Schweizer: Muster sozialer Ordnung, S. 159.

155 Vgl. Jansen: Einführung in die Netzwerkanalyse, S. 71-75. 
sich also aus der übereinstimmenden Tätigkeit als Dichterinnen und Dichter oder im Bereich der Institutionen des Literaturbetriebs sowie aus dem schriftlichen Austausch über diesbezügliche Themen. Da es sich in diesem Fall um eine große Zahl handelt (wie erwähnt, immerhin mehr als 300 Personen von über 900 Korrespondenzpartnern) und Schaukals Kontakte untereinander überwiegend informell miteinander verbunden waren, also keine organisierten Gruppen bildeten, wird kein abgeschlossenes Netzwerk erforscht. Die Netzwerke sind als „Gebilde von einer ,mittleren“ Konsistenz“ zu bezeichnen und stellen „weder einmalige und zufällige Beziehungen noch organisatorisch festgefügte Institutionen“ dar, sondern unterschiedliche, lose miteinander verbundene Gefüge. ${ }^{156}$

Die Auswahl der Akteure variiert und wird entsprechend der ,nominalistischen' netzwerktheoretischen Methode getroffen; nicht das Gruppenempfinden oder eine Institution, sondern das Forschungsinteresse bestimmt die Selektion der Personen. ${ }^{157}$ Da Richard Schaukal im Zentrum positioniert ist, handelt es sich in den meisten Fällen um die Struktur von „Ego-Netzwerken“, die auch als persönliche oder ego-zentrierte Netzwerke bezeichnet werden. ${ }^{158}$ Diese fokussieren nicht die Gesamtstruktur, sondern den personal order in einer durch persönliche und direkte Kontakte geprägten Lebenswelt des Individuums. ${ }^{159}$ „Je größer das Netzwerk ist, je mehr Alteri darin vertreten sind, die sich nicht kennen, und je verschiedenartiger die Alteri in Bezug auf ihre sonstigen Merkmale sind, desto leistungsfähiger ist ein Ego-Netzwerk als Informationslieferant, und desto stärker ist seine mobilisierende, verändernde Wirkung auf ein Individuum."160 Mit Blick auf die Netzwerke, in denen sich Schaukal bewegte, soll ebenjene Leistungsfähigkeit überprüft und die Frage beantwortet werden, wie sich die Vernetzung auf seine schriftstellerische Tätigkeit auswirkte.

Personen-Netzwerke werden von Akteuren (Knoten) gebildet, ihre Verbindungen (Kanten) sind ausschlaggebend für die Netzwerkabgrenzung. Hinzukommen neben den unterschiedlichen Positionen der Akteure in den Netzwerken (zentral oder peripher) - weitere relationale Merkmale der Kanten, die das Netzwerk strukturieren. Dazu zählen

(1) symmetrische und asymmetrische Verbindungen unter den Akteuren,

(2) die Dichte der Netzwerke,

(3) uniplexe und multiplexe Austauschbeziehungen sowie

(4) starke und schwache Konnexe.

156 Osterhammel: Die Verwandlung der Welt, S. 1010.

157 Vgl. Jansen: Einführung in die Netzwerkanalyse, S. 72.

158 Schweizer: Muster sozialer Ordnung, S. 169.

159 Vgl. Jansen: Einführung in die Netzwerkanalyse, S. 43-44.

160 Jansen: Einführung in die Netzwerkanalyse, S. 44. 
Ad (1). Von symmetrischen Verbindungen zwischen Akteuren ist die Rede, wenn der Informations- und Wissensfluss im Netzwerk in zwei Richtungen verläuft. Asymmetrische Verbindungen bezeichnen hingegen solche, in denen Akteure Informationen nur empfangen oder nur senden. In der Symmetriestruktur liegt ein entscheidender Hinweis auf die Machtpositionen von Akteuren und auf die Hierarchie in Netzwerken, die bisweilen den objektiven Wahrnehmungen diametral entgegenlaufen. ${ }^{161}$

Ad (2). Die Dichte von Netzwerken lässt sich anhand der Frequenz und der Intensität der Verbindungen zwischen den Akteuren messen. Damit hängt die Unterscheidung von uniplexen und multiplexen Netzwerken zusammen.

Ad (3). Multiplexe Netze zeichnen sich durch eine Vielzahl unterschiedlicher relationaler Verbindungen aus. Wenn Arbeitskollegen in einem Verwandtschaftsund Freundschaftsverhältnis stehen, ergibt sich eine multiplexe Struktur. Ein hoher Grad an Konformität, soziale Kontrolle und tendenzielle Konfliktlösungsbereitschaft sind die kognitiven Merkmale multiplexer Verbindungen. In uniplexen Netzwerken ergeben sich häufiger Interessenskonflikte, die zu offenen Auseinandersetzungen führen können, da der sozialen Beziehung zum verbundenen Akteur ein geringerer Wert beigemessen wird als der Erfüllung eigener Interessen. In Zusammenhang mit den uni- und multiplexen Netzwerken steht die Unterscheidung zwischen starken und schwachen Beziehungen.

Ad (4). Zu den starken Relationen zählen zum Beispiel Freundschaften und persönliche Bekanntschaften. Flüchtige Bekannte gehören hingegen zur Kategorie der schwachen Beziehungen. Nun ist aber nicht davon auszugehen, dass starke Beziehungen eine günstigere Position und mehr Informationsfluss im Netzwerk bedeuten, wie Mark Granovetter festhält, der die Begriffspaare strong ties und weak ties für die Netzwerkforschung prägte. ${ }^{162}$ Granovetter untersuchte, auf welche Informationskanäle Personen zurückgreifen, um relevante Hinweise zum Beispiel für die Jobsuche einzuholen. Dabei erkannte er die Stärke schwacher Beziehungen. Zur Stärkung der eigenen Position und für einen essentiellen Informationsgewinn sind weak ties förderlicher, zumal wenn sie zu statushöheren Kontaktpersonen unterhalten werden. Während der Informationsgehalt im

161 So befinden sich beispielsweise Sekretärinnen und Sekretäre in Betrieben nicht selten in unsichtbaren, aber zentralen Machtpositionen. Sie nehmen eine Brückenfunktion zwischen (den Clustern) der Geschäftsleitung und den Angestellten ein, erhalten relevante Informationen aus beiden Teilnetzwerken und regulieren den Informationsfluss. Daher können sie auch als ,Kristallisationspunkte ' bezeichnet werden, die darüber entscheiden, wie symmetrisch oder asymmetrisch die Kanten zwischen den Teilnetzwerken verlaufen.

162 Mark Granovetter: The Strength of Weak Ties. In: American Journal of Sociology 78 (1973), S. 1360-1380. 
Austausch mit nahen Bekannten oder innerhalb einer Clique bereits vorhandenes Wissen stärkt, Informationen also in denselben Bahnen zirkulieren und Netzwerke sich somit abschotten, eröffnen die schwachen Verbindungen ein breiteres (etwa berufliches) Potential und legen den Weg für neue Informationskanäle und weitere Netzwerke überhaupt erst frei. ${ }^{163}$ Eine uniplexe und schwache Verbindung bestand zwischen Schaukal und Thomas Mann, wie noch näher ausgeführt wird, und sie war mitverantwortlich für die Themenwahl in den Briefwechseln sowie letztlich auch für das Ende des Kontaktes.

Das Phänomen der Vorteile schwacher Beziehungen lässt sich auf die kulturelle Sphäre übertragen. Avantgardistische Strömungen entstanden erst durch ihre weitreichende Vernetzung im gesamteuropäischen Kontext. Zentren der Avantgarde ähnelten sich strukturell und wiesen in aller Regel eine „transnationale, tendenziell mehrsprachige Identität“ auf sowie eine „kulturell-künstlerische Mobilität ihrer Protagonistinnen und Protagonisten“, ${ }^{164}$ die zum Großteil in eher schwachen Relationen zueinander standen.

Schaukals Kontaktpflege beruhte meist auf dem Schriftverkehr, auch wenn die Akteure in Wien lebten. Seine Verbindungen deuten auf eine den weak ties entsprechende Vernetzung hin. Somit ergibt sich die zu prüfende These, ob der Dichter die Position eines cut point zwischen eng vernetzten Cliquen eingenommen hat. Die Rolle des cut point beschreibt Dorothea Jansen folgendermaßen: „Er ist der typische Abweichler, Modernisierer und Innovateur, der Ideen aus mehreren voneinander getrennten Kontexten zusammenfügt. [...] Er ist ein Chamäleon, das heute so und morgen so agiert.“165

\subsection{Netzwerktheorie-Modell nach Thomas Schweizer}

Der Ethnologe Thomas Schweizer erstellte aus unterschiedlichen Netzwerktheorien ein einheitliches Modell, das aus fünf ,Bausteinen` besteht. Dabei schlägt er für eine auch die zeitlichen Veränderungen miteinbeziehende dynamische Netzwerkanalyse zuerst die Umwelt zu einem bestimmten Zeitpunkt als Ausgangselement vor. Neben den ökologischen, physikalischen und demographischen Faktoren zählen dazu kulturelle sowie zeittypische soziale und politische

163 Vgl. Jansen: Einführung in die Netzwerkanalyse, S. 106-107.

164 Primus-Heinz Kucher: Einleitende Bemerkungen zur ,Moderne‘ und ,Avantgarde‘ in Österreich. In: Verdrängte Moderne - Vergessene Avantgarde. Diskurskonstellationen zwischen Literatur, Theater, Kunst und Musik in Österreich 1918-1938. Hg. von Primus-Heinz Kucher. Göttingen 2016, S. 7-18, hier S. 8.

165 Jansen: Einführung in die Netzwerkanalyse, S. 105-106. 
Diskurse. Die Relationen zwischen den Personen in einem Netzwerk, schwache und starke Beziehungen, die Stellung des Akteurs in seinem sozialen Umfeld und die Beschaffenheit der Verbindungen fasst Schweizer im zweiten Baustein zusammen, der Struktur des sozialen Netzwerks. Die Umwelt beeinflusst sowohl die Struktur als auch den dritten Baustein des Modells, die Kognitionen. Darunter werden Handlungspläne, bestimmte Vorstellungen, Überzeugungen und ,kulturgeprägte Emotionen' verstanden. Die Kognitionen beeinflussen wiederum gemeinsam mit der Struktur des sozialen Netzwerks die Interessen der Akteure, also die aufgrund der Netzwerkstruktur und Kognitionen als realisierbar und erstrebenswert eingeschätzten Ziele der Individuen. Die Interessen stehen wiederum vor dem fünften und letzten Baustein, den Handlungen, die Schweizer allgemein als Analyseziel festlegt. ${ }^{166}$ Für Schaukal würde diese Handlung ein ökonomisch unabhängiges und künstlerisch erfolgreiches Wirken als Dichter bedeuten. Zusammengefasst handelt es sich also um diese fünf Kategorien:

(1) die Umwelt,

(2) die Struktur des sozialen Netzwerks,

(3) die Kognitionen der Akteure,

(4) die Interessen der Akteure,

(5) ihre Handlungen.

Diese fünf Bausteine der Netzwerkanalyse stehen in keinem zwingenden Abhängigkeitsverhältnis, sondern gelten „probabilistisch““. ${ }^{167}$ Auch eine feste Reihenfolge der zu untersuchenden Elemente spielt keine Rolle. Es ist hier nicht das Ziel, diachrone Veränderungen des Netzwerks in einer empirischen Längsschnittstudie zu untersuchen. Der Weg der fünf Bausteine führt nicht zielgerichtet vom Diskurs zur Handlung, sondern analysiert punktuell die soziale Welt, die Handlungsspielräume der Akteure und die Strukturen, in denen sie sich befinden.

Die Netzwerkforschung ermöglicht eine je nach methodischer Vorgehensweise divergierende Schwerpunktsetzung auf Akteure (Knoten), Verbindungen (Kanten) oder die Gesamtstruktur eines Netzwerkes. Sie verzeichnet die Netzwerkzugehörigkeit von Akteuren, untersucht Verhaltensweisen und den konkreten Nutzen der Kontakte sowie die im Netzwerk kursierenden (literarischen) Diskurse.

166 Vgl. Schweizer: Muster sozialer Ordnung, S. 147-149; Kursivsetzung wie im Orig. 167 Schweizer: Muster sozialer Ordnung, S. 150. 


\section{Soziale Welt und geistiger Raum}

Pierre Bourdieus Verbindung von literaturwissenschaftlicher und soziologischer Analyse sowie seine Ausführungen zu Feld und Habitus haben Untersuchungen angeregt, die über den textstrukturellen Rahmen hinaus auch soziale Bedingungen literarischer Produktion reflektieren. Norbert Christian Wolf greift in seiner Studie über Robert Musil auf Bourdieus Sozioanalyse literarischer Texte zurück. Ausgehend von Marcel Reich-Ranickis „affektgesteuerter Abrechnung“168 mit dem Roman Der Mann ohne Eigenschaften und seinem angeblich „gescheiterten“169 Verfasser legt Wolf den Fokus auf die „Rekonstruktion der sozialen und künstlerischen Voraussetzungen und Konstellationen“"170 des Werks, um die Kategorien Erfolg und Misserfolg neu zu bewerten.

Der in Die Regeln der Kunst (1992; dt. 1999) dargelegte Feldbegriff stellt eine Sonderform der Feldtheorie dar und bedarf einer näheren Erläuterung. Bourdieu untersucht darin Gustave Flauberts Roman L'Éducation sentimentale (1869) nicht anhand des sozialen Kontextes, in dem er entstanden ist. Er geht im Umkehrschluss davon aus, dass der Text Einblicke in die Struktur des gesellschaftlichen Umfeldes liefert, in dem Flaubert sich bewegte, als er L'Éducation sentimentale schrieb. ${ }^{171}$ Bourdieu vergleicht die im Roman beschriebenen Felder (Kunst, Politik, Ökonomie) und ihre Akteure mit Flauberts Positionen und Feldern zur Zeit des Zweiten Kaiserreichs. Biographische Laufbahnen und die sozialen Bewegungen der Protagonistinnen und Protagonisten überträgt Bourdieu auf einen Stadtplan von Paris, um die Dynamik der Schauplätze im Roman mit den sozialen Räumen zu vergleichen, in denen sich Flaubert bewegte. ${ }^{172}$

Das Werk und die in den unterschiedlichen Feldern agierenden Figuren spiegeln sich im sozialen wie topographischen Raum. Die Struktur des Textes und die der Niederschrift vorgereihte Struktur der Felder erhellen und beeinflussen sich wechselseitig. ${ }^{173}$ Dies vollzieht sich jedoch nicht als passive Bewegung; die Reproduktion der sozialen Welt im literarischen Text ist, so Wolf, eine „aktive Konstruktionsarbeit““ ${ }^{174}$ Damit widersetzt sich Bourdieu dem Postulat der

168 Norbert Christian Wolf: Kakanien als Gesellschaftskonstruktion. Robert Musils Sozioanalyse des 20. Jahrhunderts. Wien u. a. 2011, S. 17.

169 Wolf: Kakanien als Gesellschaftskonstruktion, S. 15.

170 Wolf: Kakanien als Gesellschaftskonstruktion, S. 18.

171 Vgl. Wolf: Kakanien als Gesellschaftskonstruktion, S. 43.

172 Vgl. Pierre Bourdieu: Die Regeln der Kunst. Genese und Struktur des literarischen Feldes. Aus dem Franz. von Bernd Schwibs und Achim Russer. Frankfurt am Main 2001, S. 77.

173 Vgl. Wolf: Kakanien als Gesellschaftskonstruktion, S. 43.

174 Wolf: Kakanien als Gesellschaftskonstruktion, S. 47. 
Autonomie von literarischen Texten und der Auffassung, dass diese nur literaturwissenschaftlich gelesen oder interpretiert werden könnten. ${ }^{175}$ Auf der anderen Seite misst der Soziologe mit seiner Methode dem literarischen Werk einen wesentlichen Nutzen für die Sozioanalyse bei. Mehr noch, Bourdieu wertet das literarische Schreiben auf, denn es vermag ,die gesamte Komplexität einer Struktur und Geschichte, die die wissenschaftliche Analyse mühsam auseinanderfalten und entwickeln muß, in der konkreten Singularität einer sinnlichen wie sinnlich erfaßbaren Gestalt und eines Abenteuers [...] zu konzentrieren und zu verdichten." ${ }^{176}$ Die Arbeit an der Form und die rein ästhetische Kontur literarischer Texte sind für Bourdieu essentielle Faktoren für die Hervorbringung der dargestellten Welt. ${ }^{177}$ Sie wird als gelungen betrachtet, wenn sie ein sinnliches Nachempfinden ermöglicht.

Für Bourdieu stellt die soziale Welt eine abstrakte räumliche Entität dar, die sich aus dynamischen Feldern zusammensetzt (zum Beispiel ,Kultur' oder ,Bildung`), welche sich wiederum in Subfelder unterteilen lassen (zum Beispiel ,Literatur' oder ,Universität‘). ${ }^{178}$ Gleich einem physikalischen Kraftfeld stehen sie dauerhaft unter Spannung, da die darin agierenden Akteure nach dem bestmöglichen Platz streben (im Wesentlichen nach materiellem und ideellem Erfolg), sich innerhalb des Feldes also zu etablieren versuchen. Hinzu kommt, dass die Akteure in jedem Feld - und auch ihre Beziehungen zu diesem Feld - eine je eigene Disposition aufweisen, eine nur auf dieses Feld ausgerichtete spezifische Struktur aus Gestalt, Funktion und Geltung. Bedeutung und Wert der Praktiken eines jeden Akteurs können, wenn sie von einem Feld auf ein anderes übertragen werden, in ihr Gegenteil umschlagen. ${ }^{179}$ Ein bildungsbürgerlicher Habitus führt beispielsweise im politischen Feld $\mathrm{zu}$ ganz unterschiedlichen, von Partei und Wählerklientel abhängigen Erfolgen.

Ausgehend von einer komplexen und relationalen Feldstruktur der sozialen Welt, in der sich Personen in und zu den Feldern sowie zu allen beteiligten Akteuren (selbst) positionieren, verwirft Bourdieu die geschichtsphilosophische Annahme von linearen Lebenswegen, die in der modernen Erzählliteratur seit William Faulkners (1897-1962) The Sound and the Fury (1929) zurückgewiesen

175 Vgl. Bourdieu: Die Regeln der Kunst, S. 10.

176 Bourdieu: Die Regeln der Kunst, S. 53.

177 Vgl. Bourdieu: Die Regeln der Kunst, S. 179.

178 Vgl. Bourdieu: Die feinen Unterschiede, S. 277. In dieser Arbeit wird von einer weiteren Unterteilung in Subfelder abgesehen. Bourdieu ordnet dem kulturellen Feld die Subfelder ,Literatur‘, ,Musik‘ und ,bildende Kunst‘ zu.

$179 \mathrm{Vgl}$. Bourdieu: Die feinen Unterschiede, S. 164. 
worden sei. ${ }^{180}$ Bereits in Die feinen Unterschiede (1979; dt. 1982) bezeichnet der Soziologe Leben als „Bündel ungefähr gleich wahrscheinlicher, zu ungefähr gleichwertigen Positionen führender Lebensläufe." Der ererbte Kapitalumfang eines jeden Akteurs bildet die Basis seines/ihres individuellen „Möglichkeitsfeldes“. ${ }^{181}$ Dabei stelle der Lebenslauf keine zielgerichtete Kontinuität dar, er strebt nicht von einem Urgrund (raison d'être) zu seiner Vollendung (telos), sondern ist die Abfolge von wechselnden Positionen, welche die Akteure in der sozialen Welt, die man sich als dreidimensionalen Raum (oder nach Bourdieu auch als U-Bahn-Netz beziehungsweise Stadtplan) vorstellen kann, einnehmen. Der Eigenname bildet die trügerische biographische Konstante innerhalb dieses kontinuierlichen Positionenwechsels. ${ }^{182}$ Alle Startpositionen führen mit derselben Wahrscheinlichkeit zu allen möglichen Endpositionen, wobei individuelle und kollektive Krisen (zum Beispiel Kriege) stärkere Devianzen im Lebenslauf hervorrufen können. ${ }^{183}$

Der Kampf um eine günstige Position und ihre Wahrung ist verbunden mit dem Konflikt zwischen den im Feld ,Etablierten“ und den ,Aufstrebenden', daraus ergibt sich die erwähnte physikalische Spannung. Die ,Etablierten` investieren kontinuierlich die ihnen zur Verfügung stehenden Mittel, um den ,aufstrebenden Akteuren den Zugang in die Felder zu verwehren, die sie als ihre hereditär angestammten Wirkungsstätten oder neu eroberten Einflusssphären betrachten. In dieser Auseinandersetzung ist die Verfügung über und das Wissen um die Anwendungsmöglichkeiten der Kapitalsorten von entscheidender Bedeutung. Sie sind der Einsatz oder „Trumpf“ ${ }^{184}$ den jeder Akteur für die laufende Optimierung seiner Position zu leisten imstande ist. ${ }^{185}$ Bourdieu untergliedert diese Einsatzmittel in soziales, ökonomisches, kulturelles und symbolisches Kapital, das ererbt oder erworben und von einem Feld auf das andere übertragen werden kann. Die Kapitalsorten sind ungleich und zu einem Großteil auf Basis kontingenter Begebenheiten verteilt (beispielsweise Herkunft, Erbe).

Voraussetzung für das Funktionieren der im Feld vorherrschenden Dynamiken ist die Illusio, ein Konsens darüber, dass und welche Spielregeln im jeweiligen Feld gelten und welchen Wert die Kapitalsorten darin aufweisen. Der Wille zur gesellschaftlichen Teilhabe und die Bereitschaft, an die Wichtigkeit und die

180 Vgl. Bourdieu: Die biographische Illusion [1986]. In: Theorie der Biographie, S. 303-310, hier S. 305.

181 Bourdieu: Die feinen Unterschiede, S. 188; Kursivsetzung wie im Orig.

182 Vgl. Bourdieu: Die biographische Illusion, S. 304.

183 Vgl. Bourdieu: Die feinen Unterschiede, S. 188-189.

184 Bourdieu: Die Regeln der Kunst, S. 31.

185 Vgl. Bourdieu: Die feinen Unterschiede, S. 359. 
Regeln eines Spiels zu glauben, sind demnach seine entscheidenden Grundvoraussetzungen. Vermutlich spielt Bourdieu mit dem Begriff der Illusio auf die Mehrdeutigkeit des lateinischen illudere an, das etymologisch auch in seinem Aufsatz „L'illusion biographique“ (1986) anklingt und auf die Konstruktion von Gesellschaft und Lebenslauf verweist. Die Felder gleichen aber weniger einem Spielfeld als einem soziologischen Markt, in dem die Kapitalsorten ungleich verteilt sind.

Bourdieu betrachtet Habitus als erlernbaren Ausdruck, der Praktiken erzeuge, welche die Zugehörigkeit zu einer bestimmten Klasse stiften und diesen sozialen Standpunkt auch nach außen vertreten. So gehört das literarische Schreiben und die Wahl der Gattung zu Praxisformen, die zugleich auch Distinktionsmerkmale sind. Künstlerische Tätigkeit kann etwa eine bewusste soziale Abgrenzung von handwerklichen oder sportlichen Aktivitäten sein. Andererseits distanzierten sich zur Zeit der Moderne ,Dichter“ auch von ,Schriftstellern‘, die als Trivialautoren angesehen wurden. Neben der Neigung und (auch ökonomischen) Fähigkeit, diese Distinktionspraktiken anzuwenden oder sich anzueignen, spielt der Geschmack eine wesentliche Rolle für das mit dem Habitus konform gehende Ineinandergreifen von inkorporierten und objektivierten Merkmalen, die insgesamt den klassenspezifischen Lebensstil prägen. Es ist an dieser Stelle bereits auf Schaukals Dispositionssystem hingewiesen worden, welches sich aus dem ideellen wie materiellen Umgang mit Lesen und Schreiben sowie aus seiner Ausdrucksweise, der Einrichtung seines Hauses und dem Kleidungsstil zusammenfügt.

Die Verbindung von Autor-Habitus und der literarischen Darstellung des Habitus ist in Schaukals Dandyroman Andreas von Balthesser augenscheinlich. Bourdieu erläutert in diesem Kontext das Zusammenspiel von Werk und Schöpfer mit den Begriffen opus operatum und modus operandi. Zwischen dem erund bearbeiteten Werk (opus operatum) sowie der Art und Weise des Er- und Bearbeitens (modus operandi) besteht ein Wechselverhältnis, das den Habitus des Schöpfers in die Struktur seines Werkes übersetzt. Aus diesem lassen sich wiederum Rückschlüsse auf den Lebensstil des Verfassers ziehen. In ,Opus“ und ,Modus‘ zeichnet sich der ganze Mensch ab, seine Weltanschauung und Arbeitsmoral. Bourdieu veranschaulicht dieses Prinzip anhand der Tätigkeit eines Kunsttischlers. In dieser verbinde sich der Lebensstil mit den Charaktereigenschaften zu einem individuellen Dispositionssystem. ${ }^{186}$ Auch der „Schriftsteller als Subjekt einer literarischen Objektivierung ist demnach selbst im Sozialgefüge des literarischen Feldes zu objektivieren“, so Wolf. Literarische Figuren

186 Vgl. Bourdieu: Die Regeln der Kunst, S. 283. 
seien dann erzählerisch glaubhaft, wenn sie mit „bestimmten habituellen Kennzeichen ausgestattet werden. “187 Die erzählerische Glaubwürdigkeit konstituiert sich wiederum aus einem nachvollziehbaren Ineinandergreifen von Opus und Modus. Dies ist bei Andreas von Balthesser gegeben, der nicht nur sich selbst, seinem Geschmack und seiner Polemik treu bleibt, sondern in seiner Figur auch soziale wie literarische Themen vereint, die für Schaukal relevant waren. Der Autor ordnet seinen Figuren

bestimmte körperliche Merkmale, eine individuelle Herkunft und Geschichte, persönliche Umgangs- und Ausdrucksformen, soziale und ökonomische Verhaltensweisen, Denkgewohnheiten, politische Präferenzen und geschmackliche Vorlieben zu, stimmt diese Zuordnungen aufeinander ab und formt sie zu einem [...] Gesamtbild, das auf eine ihm zumindest scheinbar zugrunde liegende, einheitsstiftende, generative Formel ${ }^{\text {` }}$ - eben den somit erst konstruierten Habitus - verweist. ${ }^{188}$

Der „habituelle Stil in seiner Gesamtheit“189 kehrt also in der Romanfigur wieder. Ein Teil der Ausführungen in Bourdieus Regeln der Kunst basiert auf dieser Grundannahme. Auch Sartre sah eine unmittelbare Verbindung von Stil und Weltanschauung des Autors:

Die Struktur der Sätze, der Absätze, der Gebrauch und die Stellung des Substantivs, des Verbs usw., der Aufbau der Abschnitte und die Merkmale der Erzählung - um nur einige Besonderheiten zu zitieren - verraten verborgene Voraussetzungen, die man differentiell bestimmen kann, ohne auf die Biographie zurückzugreifen. ${ }^{190}$

In ähnlicher Weise konstituiert bereits der erste Satz in Balthesser grundlegende Habitusmerkmale:

Herr Andreas von Balthesser, der im geheimen sehr berühmte Dichter des „Perseus“, der „Androgyne“, des „Korybanten“, eingeladen, in der akademischen Vereinigung der „Intellektuellen“ einen Vortrag zu halten, dessen Gegenstand seiner geneigten Wahl war überlassen worden, erschien in dem verräucherten Klubzimmer des Hotels Pinsch, mit der ihm eigenen nachlässigen Eleganz gekleidet, leicht vorgeneigt, um die schmalen rasierten Lippen das ein wenig moquante und gleichzeitig hilflose Lächeln, das er an sich so liebt. Er hatte sich verspätet [... ..$^{191}$

187 Wolf: Kakanien als Gesellschaftskonstruktion, S. 49.

188 Wolf: Kakanien als Gesellschaftskonstruktion, S. 51.

189 Wolf: Kakanien als Gesellschaftskonstruktion, S. 61.

190 Jean-Paul Sartre: Die progressiv regressive Methode [1957]. In: Theorie der Biographie, S. 233-245, hier S. 239.

191 Schaukal: Leben und Meinungen des Herrn Andreas von Balthesser. In: WE. Bd. 2: Um die Jahrhundertwende. München/Wien 1965, S. 229-312, hier S. 231. 
In Schaukals Person und in seinem literarischen Schaffen vereinen sich die von Bourdieu genannten Merkmale. Das Wissen um die Inszenierungsstrategien, wie sie in Balthesser anklingen, und ihre Wirkung auf die Positionierung in den für Schaukal besonders wichtigen Feldern der sozialen Welt, werden auch mit Blick auf das Verhältnis des Dichters zur Fotografie ersichtlich. 